\title{
Latent Heating and Cooling Rates in Developing and Nondeveloping Tropical Disturbances during TCS-08: TRMM PR versus ELDORA Retrievals*
}

\author{
MYUNG-SOOK PARK AND RUSSELl L. ElSBERRY \\ Department of Meteorology, Graduate School of Engineering and Applied Sciences, \\ Naval Postgraduate School, Monterey, California
}

(Manuscript received 9 March 2012, in final form 23 July 2012)

\begin{abstract}
Unique sets of Electra Doppler Radar (ELDORA) observations in both developing and nondeveloping tropical disturbances in the western North Pacific are used to retrieve latent heating and cooling rates. During the reintensification of Sinlaku, maximum heating rates of about $80 \mathrm{~K} \mathrm{~h}^{-1}$ are diagnosed in the upper troposphere in the region of a strong updraft and maximum cooling rates of about $-45 \mathrm{~K} \mathrm{~h}^{-1}$ are diagnosed in the lower troposphere in the region of a strong convective-scale downdraft. The southern convective burst in the pre-Nuri mission had a lower-tropospheric maximum in latent heating that was a more favorable condition for tropical cyclone formation than was the upper-tropospheric maximum in heating and the lowertropospheric maximum in cooling in the northern convective burst. Two nondeveloping tropical disturbances had deeper layers of more uniform heating and of cooling rates, and some evidence of more shallow cloud tops, that distinguished them from the developing cases.

Although the Shige et al. Tropical Rainfall Measuring Mission (TRMM) precipitation radar (PR) algorithm was only intended to be applied over large areas on longer time scales, the PR-derived latent heating profiles were compared with the ELDORA-derived profiles to reveal important mesoscale effects. Because all six cases indicated near-zero cooling rates, a new TRMM PR algorithm should be developed that would include the effects of saturated convective-scale downdrafts in tropical mesoscale convective systems (MCSs). Production of a legacy TRMM PR dataset with this improvement would be useful for diagnosing tropical cyclone formation dating back to 1998, and for specifying initial and validation conditions for numerical models in the tropics.
\end{abstract}

\section{Introduction}

Observing and understanding of the role of the mesoscale convective system (MCS) in tropical cyclone (TC) formation and intensification was one of the primary objectives in the Tropical Cyclone Structure 2008 (TCS-08) field experiment in cooperation with the The Observing System Research and Predictability Experiment (THORPEX) Pacific Asian Regional Campaign (Elsberry and Harr 2008). Two hypotheses have been proposed as to how the MCS influences TC formation. The focus in the top-down hypothesis (e.g., Bister and

\footnotetext{
* Supplemental information related to this paper is available at the Journals Online website: http://dx.doi.org/10.1175/JASD-12-083.s1.

Corresponding author address: Dr. Myung-Sook Park, Department of Meteorology, Naval Postgraduate School, 589 Dyer Road, Monterey, CA 93943.

E-mail:mpark@nps.edu
}

Emanuel 1997) is on the mesoscale convective vortex $(\mathrm{MCV})$ in the midtroposphere that is created in the stratiform cloud region because of cooling below the freezing level due to melting and evaporation of precipitation and heating aloft due to condensational heating and latent heat released as the water droplets freeze. This midtroposphere MCV is either extended down (Bister and Emanuel 1997; Ritchie and Holland 1997) or interacts with the monsoon depression circulation (Harr et al. 1996; Elsberry and Harr 2008) to form the TC inner core.

The primary focus in the bottom-up hypothesis is on a maximum in potential vorticity generated at low levels in collaboration with a strong convective updraft region called a vortical hot tower (VHT) that is assumed to be embedded in an environment of cyclonic relative vorticity (e.g., Montgomery et al. 2006). In the numerical simulations of Montgomery et al. (2006), these VHTs occur very frequently and close enough that mergers of the VHTs occur that further increase the low-level potential vorticity. Furthermore, the associated latent heating is presumed to lower the surface pressure on 
a larger scale that will lead to inflow and spinup of the vortex on a system scale. A distinctive feature of the Nolan (2007) numerical simulations of the bottom-up process is that the maximum in the latent heating profile is shifted lower in the troposphere in conjunction with large vertical velocities that favor spinup at lower levels. Therefore, one of the key observational requirements to distinguish between developers and nondevelopers is considered to be the vertical profile of latent heating and cooling rates in association with tropical MCSs.

Both the understanding and forecasting of TC formation and intensification have been hampered by the lack of observations over the warm, tropical ocean regions where the cyclones form. Thus, a critical observational platform in TCS-08 was the airborne Electra Doppler Radar (ELDORA), which has provided unique observations to study hypotheses for mesoscale contributions to TC formation (e.g., Houze et al. 2009; Bell and Montgomery 2010). During the TCS-08 field experiment, 23 ELDORA missions collected observations of the three-dimensional circulations and reflectivities on the convective scale (horizontal resolution as high as 0.5-1 km). Roux and Ju (1990) and Roux et al. (1993) have shown that latent heating rates associated with temperature retrievals can be estimated from the radar reflectivities and radial winds by solving for unknown terms in the advection of equivalent cloud virtual temperature using continuity equations of hydrometeors. A special focus in this study is the ELDORA observations that were obtained in nondeveloping cases as well as during developing cases.

While only a few ELDORA observations have been collected during field experiments such as TCS-08, the precipitation radar (PR) on the Tropical Rainfall Measuring Mission (TRMM; Kummerow et al. 1998) satellite in principle has the potential to provide threedimensional distributions of latent heating rates for a large fraction of the cyclone formations over the global tropical oceans since its launch in 1998. As just one example, the TRMM PR spectral latent heating (SLH) algorithm by Shige et al. $(2004,2007)$ converts the observed PR profile on a pixel domain $(5 \mathrm{~km})$ to a latent heating profile via a lookup table that was derived from cloud-resolving model (CRM) simulations. One advantage of the SLH algorithm is it uses the observed rain profile information rather than a simulated profile (Tao et al. 2006). Shige et al. (2004) only intended that the algorithm would statistically represent an average heating profile for a certain rain profile observed by the TRMM PR. Indeed, the PR SLH heating profiles on horizontal grids of about $100 \mathrm{~km}^{2}$ and on monthly averages have been shown by Hagos et al. (2010) to be correlated reasonably with sounding-based apparent heat budgets. The lookup tables of Shige et al. (2004, 2007) are based on CRM simulations of tropical cloud systems during the Tropical Ocean and Global Atmosphere Coupled Ocean-Atmosphere Response Experiment (TOGA COARE), which did not include various stages of TCs as in the TCS-08.

In this study, it will be demonstrated by comparison with the ELDORA retrievals that the SLH algorithm is missing evaporative cooling rates in the lower troposphere. This demonstration is not intended to unfairly criticize the SLH, which was not designed to resolve the mesoscale physical processes in TCs. Rather, the comparisons with the ELDORA retrievals will illustrate that the saturated convective-scale downdraft as defined by Zipser (1977) is the missing physical process leading to the near-zero TRMM PR evaporative cooling rates in the lower troposphere. It will therefore be proposed that a new TRMM PR algorithm should be developed that includes the effects of the saturated convective-scale downdrafts in tropical MCSs. It is proposed that these ELDORA observations in six cases of tropical cyclones in various stages of development may provide guidance as to the latent heating and cooling rates in different tropical environments that should be replicated in the proposed new TRMM PR algorithm.

The methodology for retrieving latent heating and cooling rates from the ELDORA observations and from the TRMM PR will be summarized in section 2. Only six ELDORA missions during TCS-08 had somewhat coincident TRMM PR observations in space and time (Table 1). The foci in this study are the net heating rate profiles over a larger area (e.g., $2^{\circ}$ latitude $\times 2^{\circ}$ longitude) and the mesoscale contributions revealed by the ELDORA during two cases in the developing state (case 1: prior to the Typhoon Sinlaku reintensification and case 2: two convective burst regions in pre-Nuri) and two nondeveloping tropical disturbances (cases 3 and 4). The missing MCS contributions associated with convective updrafts and downdrafts will be investigated in highreflectivity regions (e.g., $>40 \mathrm{dBZ}$ ). [A detailed discussion and additional figures of the ELDORA observations of the outer rainbands during the mature stages of Typhoons Jangmi (case 5) and Sinlaku (case 6) are available in the supplemental material.] The TC-developing cases, nondeveloping cases, and mature-stage outer rainband cases are discussed in sections 3-5, respectively. The summary and conclusions are given in section 6 .

\section{Data and methodology}

\section{a. ELDORA latent heating rate algorithm}

The latent heating retrieval from the ELDORA observations involves two complex procedures: an estimation 
TABLE 1. Six cases during TCS-08 in which ELDORA observations in developing and nondeveloping TCs and in mature-stage outer rainbands are available to be compared with TRMM PR observations. Case 1 is during the early reintensification stage of Sinlaku; cases $2 \mathrm{a}$ and $2 \mathrm{~b}$ are the northern and southern convective systems of the pre-TD Nuri circulation, respectively; cases 3 and 4 are two nondeveloping circulations; and cases 5 and 6 are Typhoons Jangmi and Sinlaku for outer rainbands. The ELDORA case number, date, and time are given in the third, fourth, and fifth columns, respectively; and the corresponding PR overpass date and time are given in the seventh and eighth columns, respectively. A characterization of the agreement in space and in time is given in the ninth column.

\begin{tabular}{|c|c|c|c|c|c|c|c|c|}
\hline \multirow[b]{3}{*}{ TC circulation stages } & \multirow[b]{3}{*}{ Case No. } & \multirow{2}{*}{\multicolumn{3}{|c|}{ ELDORA analysis lag }} & \multirow{2}{*}{\multicolumn{3}{|c|}{ PR correlated }} & \multirow{3}{*}{$\begin{array}{c}\text { Space and time collocations } \\
\text { Time difference } \\
\text { Earlier-later sensor }\end{array}$} \\
\hline & & & & & & & & \\
\hline & & No. & Date & Time (UTC) & No. & Date & Time (UTC) & \\
\hline \multirow[t]{6}{*}{ Developing } & Case 1 & E1 & 17 Sep & $0140-0200$ & $\mathrm{P} 1$ & 16 Sep & 1700 & Long (9 h) \\
\hline & & & & & & & & PR-ELDORA RF13 \\
\hline & Case $2 \mathrm{a}$ & $\mathrm{E} 2$ & 16 Aug & $0000-0300$ & $\mathrm{P} 2$ & 16 Aug & 0700 & Long $(7 \mathrm{~h})$ \\
\hline & & & & $0030-0100$ & & & & ELDORA RF2-PR \\
\hline & Case 2b & E3 & & $0315-0345$ & P3 & & & Short $(3.5 \mathrm{~h})$ \\
\hline & & & & & & & & ELDORA RF2-PR \\
\hline \multirow[t]{4}{*}{ Nondeveloping } & Case 3 & $\mathrm{E} 4$ & 29 Aug & $0300-0330$ & P4 & 29 Aug & 0810 & Short $(4.5 \mathrm{~h})$ \\
\hline & & & & & & & & ELDORA RF5-PR \\
\hline & Case 4 & E5 & 4 Oct & 0200-0230 & P5 & 3 Oct & 1643 & Long $(10 \mathrm{~h})$ \\
\hline & & & & & & & & PR-ELDORA RF23 \\
\hline \multirow[t]{5}{*}{ Mature } & Case 5 & E6 & 26 Sep & $2320-2340$ & P6 & $26 \mathrm{Sep}$ & 2000 & Short $(3-4 h)$ \\
\hline & & E7 & 27 Sep & $2350-0000$ & & & & PR-ELDORA RF21 \\
\hline & & E8 & & $0000-0010$ & & & & \\
\hline & Case 6 & E9 & 19 Sep & $0218-0230$ & $\mathrm{P} 7$ & 18 Sep & 2048 & A little long (5.5 h) \\
\hline & & & & & & & & PR-ELDORA RF13 \\
\hline
\end{tabular}

of precipitation and wind through Doppler radar analysis, and a combined dynamic and thermodynamic retrieval (called thermodynamic retrieval). A detailed description of the thermodynamic retrieval algorithm, which is based on Roux et al. (1993), is given in appendix $A$ and the uncertainties are analyzed in appendix B. First, quality-controlled ELDORA observations were obtained from the National Center for Atmospheric Research (NCAR) Earth Observing Laboratory and initially corrected for navigation errors (Bosart et al. 2002). These files were both automatically and manually edited using an algorithm called SOLO II (Oye et al. 1995) to remove noise, ocean returns, and radar artifacts. The edited reflectivities and Doppler velocities were then interpolated to a Cartesian grid with a horizontal interval of $1 \mathrm{~km}$ and a vertical interval of $500 \mathrm{~m}$.

A key step in the radar analysis is the application of a variational minimization technique (Reasor et al. 2009) to map the Doppler information to the gridded threedimensional wind field while simultaneously enforcing as weak constraints a mass continuity equation, a specification of zero second derivatives of the wind field, and vertical velocity boundary conditions. Matejka and Bartels (1998) showed the variational solution contributed to low vertical velocity errors for the ELDORA sampling strategy. The weighting value for the mass constraint $\lambda_{\mathrm{mc}}$ was set at 1000 , which is considered the best for the $1 \mathrm{~km} \times 1 \mathrm{~km}$ horizontal grid (M. Bell 2012, personal communication; Reasor et al. 2009). Since unreasonably large vertical velocities were calculated under the aircraft in some cases, this region was excluded from further analysis to focus on more reliable values away from the flight track.

As the aircraft flies around (or back and forth in advance of) a convective burst region, the ELDORA forward- and backward-pointed antennas sweep over a grid point many times with different viewing angles. The maximum time lag among the measurements is about 5-10 min, depending on beam angles and the distance from flight tracks (Hildebrand et al. 1996). At any one instant, the inferred vertical velocity may be quite large (e.g., within a strong updraft or strong downdraft). However, the variational minimization with a mass continuity constraint applied over a threedimensional area that is sampled by several measurements will reduce the temporal variability. Thus, the vertical velocities being derived for use in the latent heating algorithm are not the instantaneous values; for example, they do not apply on the time scale of the radar beam sweep of $3 \mathrm{~s}$ or a time step of the 1-km model grid as in Fig. 2a of Park et al. (2013). Especially for the larger convective features that are tens of kilometers wide, vertical velocities are considered to be representative of time scales of up to $5-10$ min by the multiple Doppler observations. 
The ELDORA latent heating rate $Q_{\text {ELD }}$ values have uncertainties highly dominated by the retrieval of vertical velocity $W$ in (A15), since the correlation of $Q_{\mathrm{ELD}}$ and $W$ is 0.8 for the case of Typhoon Jangmi rainband considered in the sensitivity analysis in appendix B. As in the previous studies (e.g., Houze et al. 2009; Bell and Montgomery 2010; Guimond et al. 2011), the ELDORA reflectivity values have not been corrected for attenuation. However, the variational method uses the maximum reflectivity observed by either the forward- or backward-pointed antennas, so the assumption is that one of the two has a better look at the precipitation and is less attenuated. Although the attenuation may limit the capability to detect scatterers beyond a region of heavy rainfall, the aircraft moves beyond heavy rainfall cells. As long as a radial wind can be detected, the vertical velocity can be calculated, and that is the most critical parameter to the retrieval of latent heating rate as in the error analyses above and in appendix B, which agrees well with Guimond et al. (2011).

In addition, the root-mean-square (RMS) uncertainty of $Q_{\mathrm{ELD}}$ in terms of $\lambda_{\mathrm{mc}}$ values is about $5.61 \mathrm{~K} \mathrm{~h}^{-1}$ with small biases (regression slope of 0.99). Uncertainties in the retrieved heating rates arising from different environmental temperature profiles are especially small with $1.27 \mathrm{~K} \mathrm{~h}^{-1} \mathrm{RMS}$ values. Errors introduced in the complicated temperature perturbation retrieval may contribute only $5 \%$ of the changes in the heating rate magnitudes (Roux et al. 1993). However, the $Q_{\text {ELD }}$ magnitudes are dependent on the horizontal resolution (appendix B) with proportionately larger values as the grid size decreases.

Another important feature in the ELDORA retrievals is the application of a three-step Leise (1982) filter, which will smooth the values in 3D space, and in particular will tend to smooth over localized time variations. Consequently, the larger $Q_{\mathrm{ELD}}$ values on the $1-\mathrm{km}$ grid have been somewhat smoothed, and thus they may be considered to be more compatible with TRMM PR latent heating rate $Q_{\mathrm{PR}}$ values with a pixel size of $5 \mathrm{~km}$.

Given the three-dimensional velocity field from the variational minimization procedure that has been spatially smoothed, latent heating and cooling profiles at each grid point are then provided from the $Q_{\mathrm{ELD}}$ retrieval procedure. The retrieval neglects the time tendencies in the hydrometeor conservation equations [(A8)-(A10)]; for example, only horizontal and vertical advective tendencies are being considered. Because the three-dimensional velocity field is calculated in a moving coordinate system, no time tendencies at a point due to translation of the cloud system are included in the retrievals. Note that these conditions are different from
Guimond et al. (2011), who did include time tendency terms from numerical model-simulated values and local variations of strong updrafts and downdrafts to retrieve the instantaneous latent heating rate. They have shown that stationarity cannot be assumed in radar retrievals on time scales of less than $3 \mathrm{~min}$. The time tendencies over such short time intervals were not possible to be observed by ELDORA along the flight track leg. The large heating rates $\left(>250 \mathrm{~K} \mathrm{~h}^{-1}\right)$ as in Fig. 12 of Guimond et al. are not being addressed in this application of the ELDORA latent heating retrieval technique.

For this reason and consideration of the various steps in the retrieval procedure, and because of some rather large time differences between the ELDORA observations and the TRMM PR overpasses (Table 1), individual convective clusters cannot be directly compared. Rather, comparisons of the latent heating rates will be in terms of contoured frequency altitude diagrams (CFADs; Yuter and Houze 1995) over areas that contain representative convective clusters.

Thus, the sensitivity study in appendix B and the above-mentioned discussion indicates the uncertainty in the $Q_{\text {ELD }}$ values primarily arises from the threedimensional velocity field from the variational minimization procedure. In the following section, it will be argued that the TRMM PR retrievals are also effectively averaged as a result of how the CRM simulation lookup table is generated.

\section{b. TRMM PR latent heating rate algorithm}

The TRMM SLH algorithm uses PR level 2 retrievals of the precipitation-top height, precipitation rates at the surface and at the melting level, and the rain type to assign a heating profile for that rain type from the CRM simulation lookup table (Shige et al. 2004, 2007). The SLH orbital algorithm has the same horizontal resolution $(5 \mathrm{~km})$ as the level 2 PR observations with a vertical resolution of $500 \mathrm{~m}$. These heating profiles for the three rain types-convective, shallow stratiform, and anvil rain (deep stratiform with a melting level)-were derived as a function of rain top height from CRM simulations of tropical cloud systems during the TOGA COARE. The CRM is the two-dimensional version of the Goddard Cumulus Ensemble model (Tao et al. 2003). These simulations employ Kessler-type twocategory liquid water (cloud water and rain) and a threecategory ice phase (cloud ice, snow, and graupel) parameterization. Observations of large-scale advective tendencies of temperature, moisture, and horizontal momentum are used as the forcing for convection in the model simulations. Consequently, the convective systems may be considered to be the steady-state response to the slowly varying, large-scale circulation, which is 
why the SLH algorithm has previously been considered as appropriate for long-term average applications.

In the Shige et al. (2007) convective heating profile, the upper-level heating due to ice processes is separately considered from the lower-level heating due to liquid water, which better represents the vertical profile of latent heating rate than the Shige et al. (2004) version. Even though the CRM simulations had both positive and negative heating profiles for convective rain type, Shige et al. (2007) chose to use an averaged positive value in the lookup table for convective rain. Therefore, a pixel that is classified as having convective rain has condensational heating throughout the tropospheric column, which is a limitation of the SLH algorithm for MCSs that is best illustrated with CFADs. A pixel that is classified as having stratiform rain has heating above freezing level and does have small evaporative cooling below the melting layer.

The profile of PR SLH latent heating rate $Q_{\mathrm{PR} \_ \text {SLH }}(z)$ is derived from

$$
Q_{\mathrm{PR} \_\mathrm{SLH}}(z)=\frac{Q_{\mathrm{LUT}}(z)}{\mathrm{RR}_{\mathrm{LUT}}(z)} \times \mathrm{RR}_{\mathrm{PR} \_ \text {v2 }}^{*}\left(z_{0}\right),
$$

where $Q_{\mathrm{LUT}}(z)$ and $\mathrm{RR}_{\mathrm{LUT}}(z)$ are the CRM-simulated heating rate and rain rate, respectively; and $\mathrm{RR}_{\mathrm{PR} \_v 2}^{*}\left(z_{0}\right)$ is the PR level 2 rain rate at a significant level. For a convective pixel, the $\mathrm{RR}_{\mathrm{PR} \_\mathrm{v} 2}^{*}\left(z_{0}\right)$ in (1) is specified as the surface rain rate when estimating the low-level convective heating magnitude and is the rain rate just above freezing level when estimating the upper-level convective heating magnitude. For a (deep) stratiform pixel, $\mathrm{RR}_{\mathrm{PR} \_\mathrm{v} 2}^{*}\left(z_{0}\right)$ is the rain rate at the melting level for upper-level heating magnitudes, and the difference of the rain rates at the surface and at the melting level is used to determine the low-level cooling magnitude. The SLH heating rates are obtained from the Japan Aerospace Exploration Agency Earth Observation Research Center for specific TRMM PR swaths that correspond to the ELDORA observations.

Shige et al. (2007, p. 1103) stated that the PR precipitation falling at a given time is related to the accumulated latent heating that led up to the precipitation over a finite period. They documented that PR latent heating and cooling rates should be basically integrated over the periods encompassing the life cycles of cloud processes producing the precipitation. Thus, the CRM-simulated rates will be considered as temporally averaged, so that the uncertainties that arise from shortterm changes in vertical velocity as described by Guimond et al. (2011) cannot addressed for the PR retrievals, which is somewhat analogous to the situation for the $Q_{\mathrm{ELD}}$ retrievals described in section 2a. Thus, the comparisons of PR retrievals and $Q_{\mathrm{ELD}}$ retrievals will include both area averages of net heating and CFADs to infer the mesoscale effects ${ }^{1}$ on the latent heating and evaporative cooling rates without consideration of the shorter cloud-scale time changes that are not resolved in either retrieval.

\section{Case studies of developing stage}

\section{a. Pre-reintensification (prerein) Sinlaku}

Typhoon Sinlaku had decayed after making landfall over Taiwan (Fig. 1a), and the remnant circulation had moved to near $27.5^{\circ} \mathrm{N}, 125.9^{\circ} \mathrm{E}$ by $0000 \mathrm{UTC}$ 17 September 2008 (Fig. 1c). The ELDORA observations of a convective burst in this circulation were collected between 0140 and 0200 UTC 17 September. As extensively analyzed by Sanabia (2010), this convective burst was the third in a sequence, and then the circulation reintensified to a typhoon after this mission with the formation of an eyewall structure (not shown). The TRMM PR observations (Table 1; Fig. 1b) were of the second convective burst about $9 \mathrm{~h}$ before the ELDORA observations, which from satellite imagery appeared to have similar characteristics as the third convective burst. Since the outer circulation of the Sinlaku remnants were similar to a monsoon depression, similar dynamical and physical processes may be occurring as in the TC formation process, and thus the case is included in the developing-stage category.

The profiles of net heating rates for the TRMM PR over the P1 area in Fig. 1b and for the ELDORA over the E1 area in Fig. 1c are provided in Fig. 2a. In this case, only the areas with reflectivities greater than $20 \mathrm{dBZ}$ are included because the TRMM PR is not sensitive below $17 \mathrm{dBZ}$ (Park et al. 2007). Above the freezing level $(\sim 5 \mathrm{~km})$, the net heating profiles have a similar shape with a maximum near $7 \mathrm{~km}$. However, the TRMM PR has a maximum heating rate about 3 times larger than the ELDORA rate and is still positive at $12 \mathrm{~km}$. A notable difference exists below $4 \mathrm{~km}$, as the TRMM PR has a positive heating and the ELDORA has net cooling.

The mesoscale contribution to the net heating aloft is revealed by examining the areas with reflectivities at $4 \mathrm{~km}$ greater than $40 \mathrm{dBZ}$ (Fig. 2b). Although the ELDORA high reflectivities greater than $40 \mathrm{~dB} Z$ occupy only about $10 \%$ of the region of reflectivities greater than $20 \mathrm{dBZ}$, the large heating and cooling in the

\footnotetext{
${ }^{1}$ This general term will be used to refer to the large heating and cooling rates associated with the convective-scale updrafts and downdrafts compared to the downdrafts in the stratiform rain.
} 

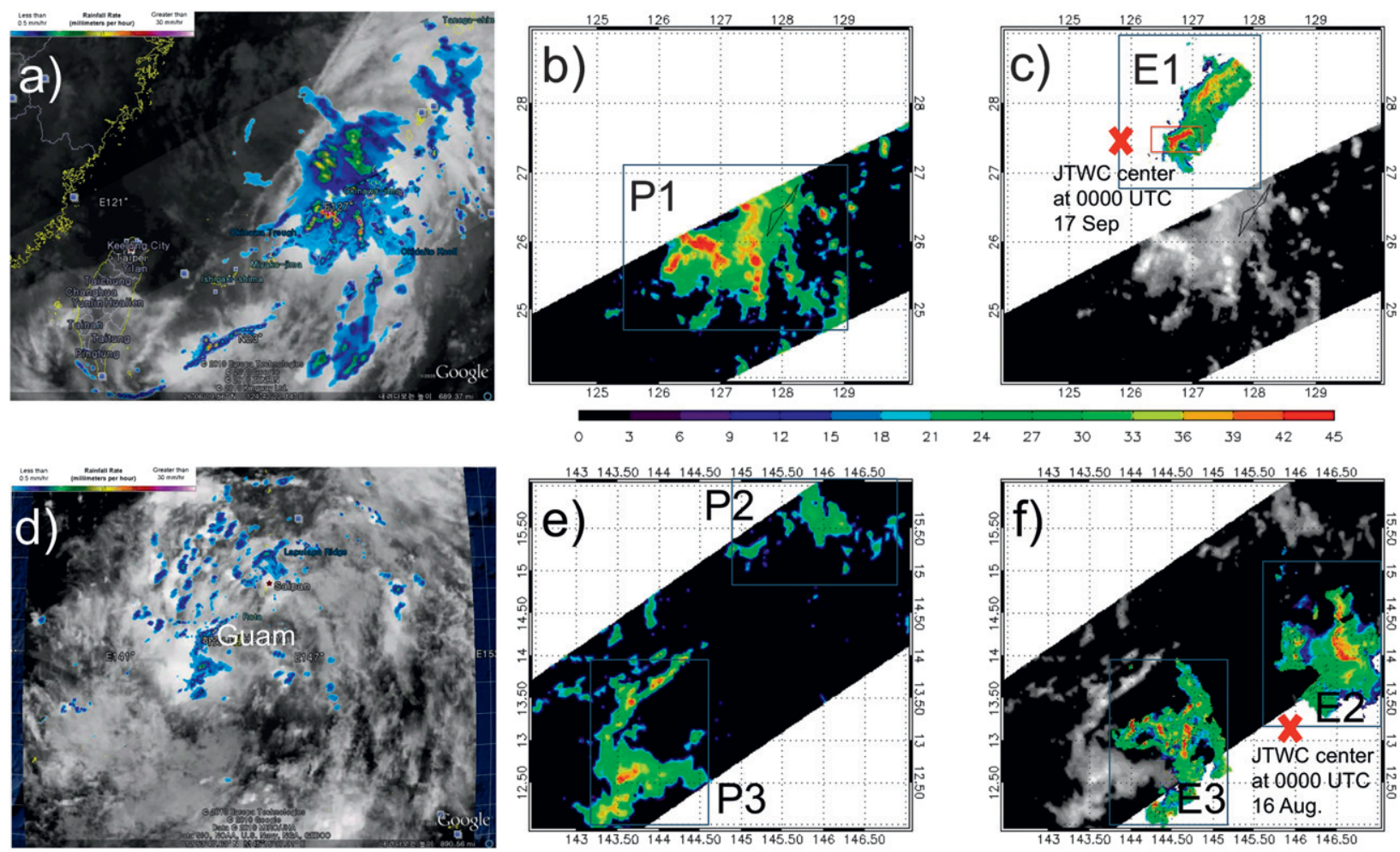

FIG. 1. The TRMM PR rain rates for (a) case 1 and (d) case 2 at the observation times in Table 1 are overlaid with the TRMM Microwave Imager (TMI) rain rates and the MTSAT infrared imagery. (b),(e) TRMM PR reflectivities (dBZ; scale between rows) at 4-km height, and the blue boxes with P numbers indicate the PR analysis domains. (c),(f) TRMM gray shade images with overlays of the corresponding ELDORA reflectivities with green ELDORA analysis boxes indicated by E numbers

high-reflectivity areas make up about $50 \%$ of the total heating profile. Note that the ELDORA net heating rate aloft is now larger than for the TRMM PR. However, the more striking difference is in the lower troposphere, where the TRMM PR has entirely positive heating and the ELDORA has a well-defined cooling rate maximum. As indicated above, Shige et al. $(2004,2007)$ did not attempt to resolve the mesoscale contributions that might be associated with reflectivities greater than $40 \mathrm{dBZ}$. Rather, they averaged the positive and negative heating rates for pixels that were judged to be convective, which then leads to a positive net heating rate throughout the column.

The CFADs (Figs. 2c and 2d) reveal more details of the vertical structure of the heating and cooling rates for case 1 . In these CFAD diagrams, frequencies are normalized by the total nonmissing pixel number of all levels for each sensor. Since the frequencies for increasing heating magnitudes likely decrease exponentially, the normalized frequencies are plotted on a logarithmic scale with values of $10^{-2}, 10^{-3}, 10^{-4}$, and $10^{-5}$. Nolan (2007) and Rogers et al. (2007) have presented similar CFAD analyses to characterize convection in TCs. In general, the majority $\left(10^{-3}\right.$ normalized frequency contour line in Fig. 2c) of the $Q_{\mathrm{ELD}}$ magnitudes are within $\pm 10 \mathrm{~K} \mathrm{~h}^{-1}$, with a tendency for offsetting heating rates and cooling rates at each elevation. By contrast, the less frequent (frequency contours $\leq 10^{-4}$ ) heating (cooling) rates range from $25(-20)$ to 80 $(-50) \mathrm{K} \mathrm{h}^{-1}$.

Consider the red box region in Fig. 1c, which has the most intense convection in the $\mathrm{E} 1$ region. Reflectivities at $4 \mathrm{~km}$ (Fig. 3b) greater than $40 \mathrm{dBZ}$ (as is applied in Fig. 2b) are found between $x=60$ and $100 \mathrm{~km}$, but this includes alternating regions with maximum heating at $8 \mathrm{~km}$ (Fig. 3a) and maximum cooling at $4 \mathrm{~km}$ (Fig. 3b). Averaged vertical profiles over intense heating region "H" with $Q_{\mathrm{ELD}}>+25 \mathrm{~K} \mathrm{~h}^{-1}$ in Fig. 3a may be compared with the background convective heating region "BG-H" with values less than $5 \mathrm{~K} \mathrm{~h}^{-1}$. Similarly, the intense cooling region "C" with $Q_{\mathrm{ELD}}<-20 \mathrm{~K} \mathrm{~h}^{-1}$ may be compared with the background evaporative cooling region "BG-C" with values between 0 and $-7 \mathrm{k} \mathrm{h}^{-1}$ (Fig. $3 b)$. These threshold values are selected to correspond to the $10^{-4}$ and $10^{-3}$ frequency contours of heating at $8 \mathrm{~km}$ (cooling at $4 \mathrm{~km}$ ) in the CFAD in Fig. 2c. Notice that 

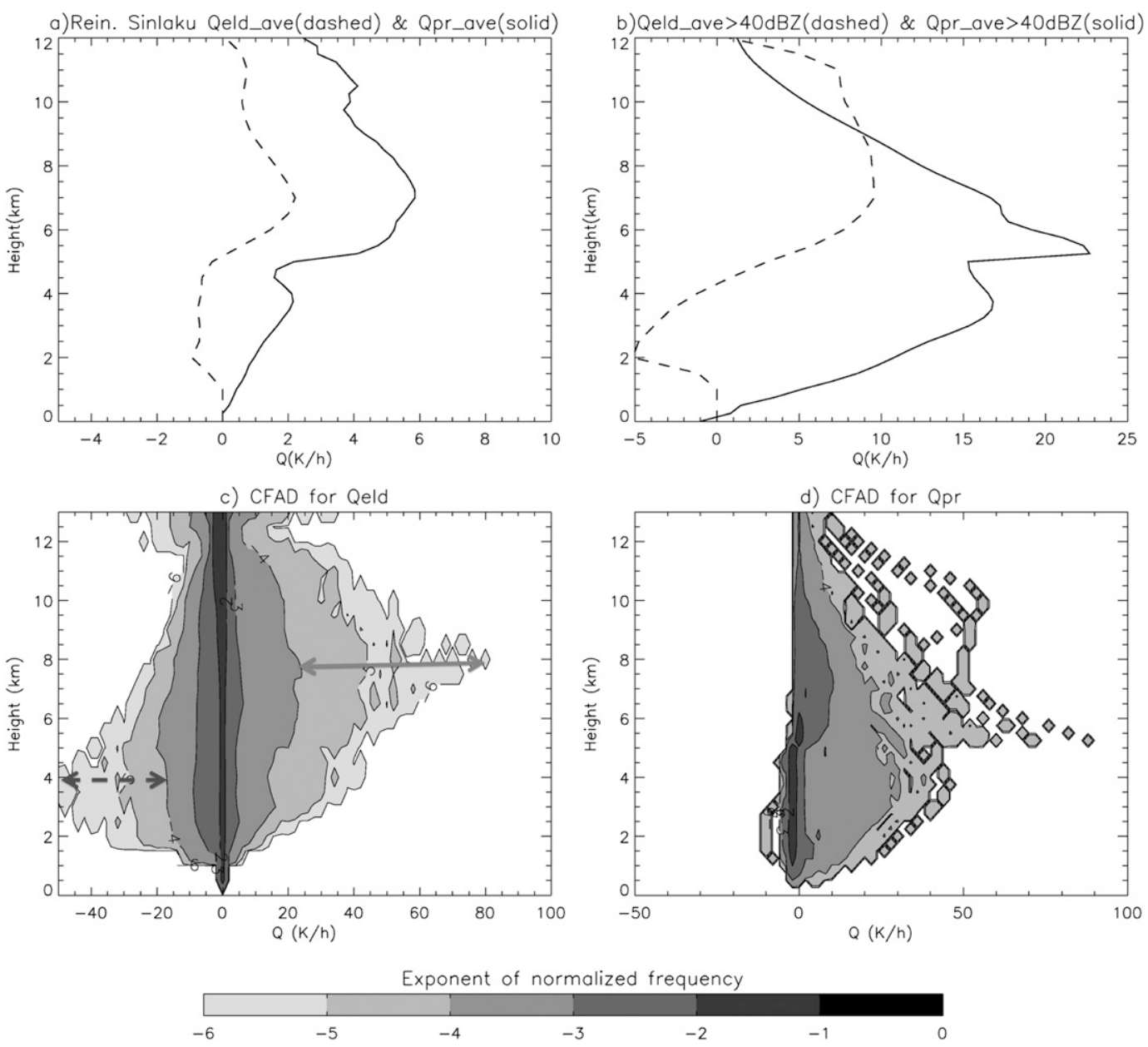

FIG. 2. (a) Net heating rate $\left(\mathrm{K} \mathrm{h}^{-1}\right)$ profiles averaged over the areas of reflectivity $>20 \mathrm{dBZ}$ for case 1 for ELDORA observations within the E1 area in Fig. 1c (dashed) and for the TRMM PR observations within the P1 area in Fig. 1b (solid). (b) As in (a), but averaged over the area of reflectivity at $3 \mathrm{~km}>40 \mathrm{dBZ}$ to highlight the mesoscale effects. Note the different abscissa scales in (a) and (b) in this and subsequent similar figures. CFADs of the (c) ELDORA-derived and (d) PR-derived latent heating rates for case 1. The frequencies are normalized by the total number of reflectivities larger than $17 \mathrm{dBZ}$ in each case, and shading increases for decreasing frequencies in powers of $10^{x}$, where the shaded bar at the bottom indicates the exponent $x$. Also, note in (b) that the less frequently occurring frequencies $<10^{-4}$ but larger magnitude of upper-level heating rates (low-level cooling rates) across the solid arrow (dashed arrow) will be shown to be associated with the $\mathrm{H}(\mathrm{C})$ region in Fig. 3a (Fig. 3b).

an elevation with a maximum $Q_{\mathrm{ELD}}$ heating or cooling rate for a specific frequency contour has a corresponding maximum in the vertical profile of heating or cooling, even though the remainder of the vertical profile does not have the same vertical structure of heating rates or cooling rates for that frequency contour.

The $10^{-3}$ normalized frequency contour in Fig. $2 \mathrm{a}$ covers about $300 \mathrm{~km}^{2}$, and the CFAD is normalized by a total of 300000 nonmissing grids $\left(1 \mathrm{~km}^{2}\right)$. By contrast, the normalized frequency contour $\leq 10^{-4}$ in Fig. 2a, which has larger heating and cooling rates but covers areas smaller than $30 \mathrm{~km}^{2}$, is associated with the $\mathrm{H}$ and $\mathrm{C}$ regions in Figs. $3 \mathrm{a}$ and $3 \mathrm{~b}$. The less frequently occurring (but strong) convective regions with much more intense heating are considered to be more important for $\mathrm{TC}$ formation and have been the focus in Houze et al. (2009) and Bell and Montgomery (2010). As indicated in Fig. 2b, such regions have large net $Q_{\text {ELD }}$ values aloft that will contribute to vertical stretching and positive potential vorticity tendencies in the column below the heating maximum. However, these regions also may have low-level maxima of evaporative cooling that will lead to negative potential vorticity tendencies. Thus, the interpretations of the CFADs in this study will highlight at what levels the less frequently occurring $\left(10^{-4}\right.$ and $\left.10^{-5}\right)$ contour 

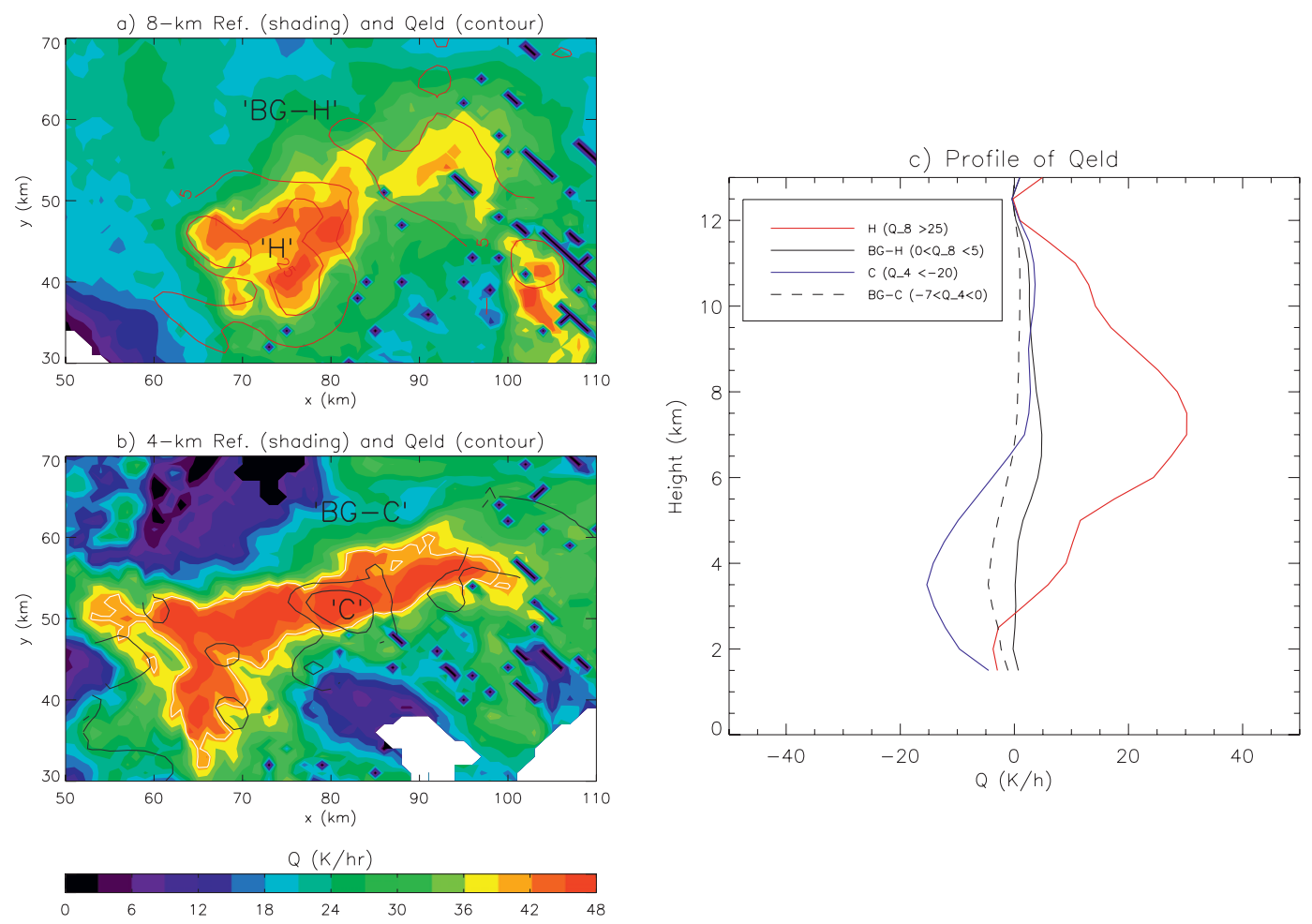

FIG. 3. Horizontal distribution of reflectivity (dBZ, shading; scale at bottom) at (a) 8-and (b) 4-km height over the E1 region shown in Fig. 1c. In (b), the region of reflectivity at $4 \mathrm{~km}>40 \mathrm{dBZ}$ as in Fig. $2 \mathrm{~b}$ is indicated as a white contour. A maximum $Q_{\mathrm{ELD}} \mathrm{H}$ region is defined by values greater than $+25 \mathrm{~K} \mathrm{~h}^{-1}$ (red contour) relative to a BG-H region with positive values $<5 \mathrm{~K} \mathrm{~h}^{-1}$, where the threshold values +25 and $+5 \mathrm{~K} \mathrm{~h}^{-1}$ are selected to correspond with $10^{-4}$ and $10^{-3}$ frequency contours at $8 \mathrm{~km}$ of the CFADs in Fig. 2. A maximum $Q_{\mathrm{ELD}} \mathrm{C}$ region with $Q_{\mathrm{ELD}}<$ $-20 \mathrm{~K} \mathrm{~h}^{-1}$ (blue contours) relative to a BG-C region with negative values $>-7 \mathrm{~K} \mathrm{~h}^{-1}$, where the threshold values are selected to correspond with $10^{-4}$ and $10^{-3}$ frequency contours at $4 \mathrm{~km}$. (c) Vertical profiles of $Q_{\mathrm{ELD}}\left(\mathrm{K} \mathrm{h} \mathrm{h}^{-1}\right)$ averaged over the $\mathrm{H}, \mathrm{BG}-\mathrm{H}, \mathrm{C}$, and $\mathrm{BG}-\mathrm{C}$ regions.

lines have their maximum positive and negative $Q_{\mathrm{ELD}}$ values.

The vertical structure of the latent heating rates and evaporative cooling rates in the ELDORA CFAD (Fig. 2a) is indicative of a vigorous MCS that was extensively analyzed by Sanabia (2010). At the time of these ELDORA observations, the remnants of Typhoon Sinlaku were moving toward the Kuroshio region but were under the influence of moderate vertical wind shear. Since Sanabia (2010) analyzed a broad updraft exceeding $30 \mathrm{~m} \mathrm{~s}^{-1}$ in the upper troposphere, the maximum heating rates of $80 \mathrm{~K} \mathrm{~h}^{-1}$ at around $8 \mathrm{~km}$ in Fig. 2c appear to be reasonable. Because of the tilted updraft in the convective cell (C region in Fig. 3b), a broad region of strong downdrafts was also present in the lower troposphere (Sanabia 2010). Thus, the large evaporative cooling rates of -25 to $-45 \mathrm{~K} \mathrm{~h}^{-1}$ in Fig. $2 \mathrm{c}$ also appear to be reasonable. Although some uncertainties exist in the $Q_{\text {ELD }}$ values due to time tendencies as described in section $2 \mathrm{a}$, the horizontal and vertical advective terms are in thermodynamic and dynamic balance with maximum upper-tropospheric heating rates and maximum lower-tropospheric cooling rates in this vigorous MCS as ex-Sinlaku was beginning to reintensify.

Comparison of the CFAD for the TRMM PR (Fig. 2d) with that for the ELDORA (Fig. 2c) illustrates what a new algorithm for the PR would need to replicate if such MCS effects were to be included. Only a very few TRMM PR pixels were associated with a maximum heating rate of $50 \mathrm{~K} \mathrm{~h}^{-1}$ in the upper troposphere. Rather, the vertical profile of the heating rates in Fig. $2 \mathrm{~d}$ generally has the shape of the net heating rates for the TRMM PR reflectivities greater than $40 \mathrm{dBZ}$ in Fig. 2b. It is very clear from Fig. 2d that a new TRMM PR algorithm must explicitly consider the evaporative cooling rates if the mesoscale contributions to tropical cyclone formation are to be resolved. In contrast to the deep layer of evaporative cooling rates inferred from the ELDORA observations, the present SLH algorithm that averaged the heating and cooling rates for convective pixels has 


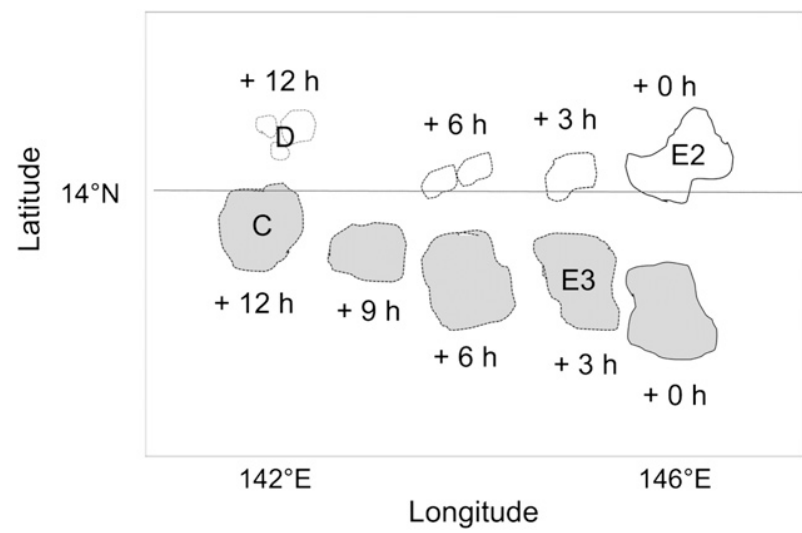

FIG. 4. Three-hourly northern and southern convective clusters evolution after 0000 UTC 16 Aug following the cluster boundaries defined as the MTSAT infrared brightness temperature $=210 \mathrm{~K}$. Whereas the convection associated with E2 dissipates after $+6 \mathrm{~h}$, a continuous connection to the convective cluster $\mathrm{C}$ exists after $+12 \mathrm{~h}$ that becomes the locus of TD Nuri.

resulted in almost zero cooling rates. Note that these differences in cooling rate profiles are so large that they cannot be explained by uncertainties in the $Q_{\text {ELD }}$ retrievals. Rather, these ELDORA observations may provide a basis for developing a new TRMM PR algorithm that includes the effects of tropical MCSs.

\section{b. Pre-Nuri (case 2)}

The pre-tropical depression (TD) Nuri circulation was centered at $13.2^{\circ} \mathrm{N}, 146.8^{\circ} \mathrm{E}$ (red cross in Fig. 1f) and moving west-northwestward at 0000 UTC 16 August according to the Joint Typhoon Warning Center (JTWC). Since the circulation became TD $13 \mathrm{~W}$ at 1800 UTC 16 August, the ELDORA and TRMM PR observations into the northern and southern convective bursts (E2 and E3 in Fig. 1f, respectively) about 18 and 15 h, respectively, prior to the formation provide a unique opportunity to compare the two retrievals for the developing stage of a TC (Table 1).

The differences in latent heating and evaporative cooling rates between the two convective bursts are important because of a difference in interpretation as to the critical convective burst that led to the formation of TD Nuri. The interpretation of Montgomery et al. (2009) is that pre-Nuri evolved from the synoptic-scale easterly wave, and specifically from the northern convective burst that was near a "sweet spot" within the "marsupial pouch" of Dunkerton et al. (2008). While the northern convective burst (E2 in Fig. 4) soon decayed in the Multifunctional Transport Satellite (MTSAT) imagery, it was the southern convective burst (E3) that continued to follow the pre-Nuri track. It is also important that a closed low-level circulation in the southern convective region was present in the 1.5-km ELDORA wind analysis [confirmed by the analysis of Cisneros et al. (2010)]. Following 1200 UTC 16 September, deep convection (labeled $\mathrm{C}$ in Fig. 4) that can be traced back in the MTSAT imagery to the southern convective burst then interacted with another convective region (labeled D) to become the locus of TD Nuri (Fig. 4). Thus, the southern convective burst (E3) will be the primary focus as the critical cloud cluster from which Nuri later forms. However, two consecutive ELDORA observations in E2 will be examined to illustrate the differences between the E2 mesoscale system that did not contribute to low-level spinup in TC formation versus the E3 mesoscale system that did contribute. Although a 4-h difference exists between the ELDORA observations and the TRMM PR for the southern convective burst, the satellite imagery on which Fig. 4 is based suggests a continuity of convective bursts during the period.

The net heating rate profile for the TRMM PR (Fig. 5a) over the P2 area in the pre-Nuri case 2 is very similar to case 1 (Fig. 2a) with positive heating at all levels. Whereas the ELDORA had net cooling for pre-Sinlaku in the $2-5-\mathrm{km}$ layer, net warming exists in the lower troposphere in the southern convective burst region of preNuri. When the mesoscale effects are highlighted by summing over the areas with reflectivities at $4 \mathrm{~km}$ greater than $40 \mathrm{dBZ}$ (Fig. 5b), the net $Q_{\mathrm{PR}}$ value is concentrated in the $0-8-\mathrm{km}$ layer (rather than extending to $12 \mathrm{~km}$ as in pre-Sinlaku) and has a sharp maximum just above the freezing level. Except for the sharp maximum, the $Q_{\text {ELD }}$ profile of net heating agrees reasonably well, and it specifically has net warming in the lower troposphere in contrast to the net cooling for the $Q_{\text {ELD }}$ in the pre-Sinlaku case (Fig. 2b).

The CFAD for the $Q_{\text {ELD }}$ (Fig. 5c) provides additional information regarding the different mesoscale effects in the southern convective burst in pre-Nuri. Notice the $10^{-4}, 10^{-5}$, and $10^{-6}$ frequency contours have maximum heating rates that are in the $2-5-\mathrm{km}$ layer rather than in the $5-10-\mathrm{km}$ layer in the pre-Sinlaku case (Fig. 2c). The corresponding frequency contours of cooling rates for pre-Nuri also have maximum values in the $2-5-\mathrm{km}$ layer. Notice also that these cooling rates are significantly reduced relative to the pre-Sinlaku case, which then contribute to the net warming in the lower troposphere for the ELDORA retrievals in Fig. 5b. As described earlier, the ELDORA radar winds detected a lower-tropospheric cyclonic circulation in association with the southern convective burst, which is consistent with the lowertropospheric maximum in net warming, because that will induce convergence in the layer below the maximum heating. This different mesoscale heating profile for the southern convective burst in the pre-Nuri case 

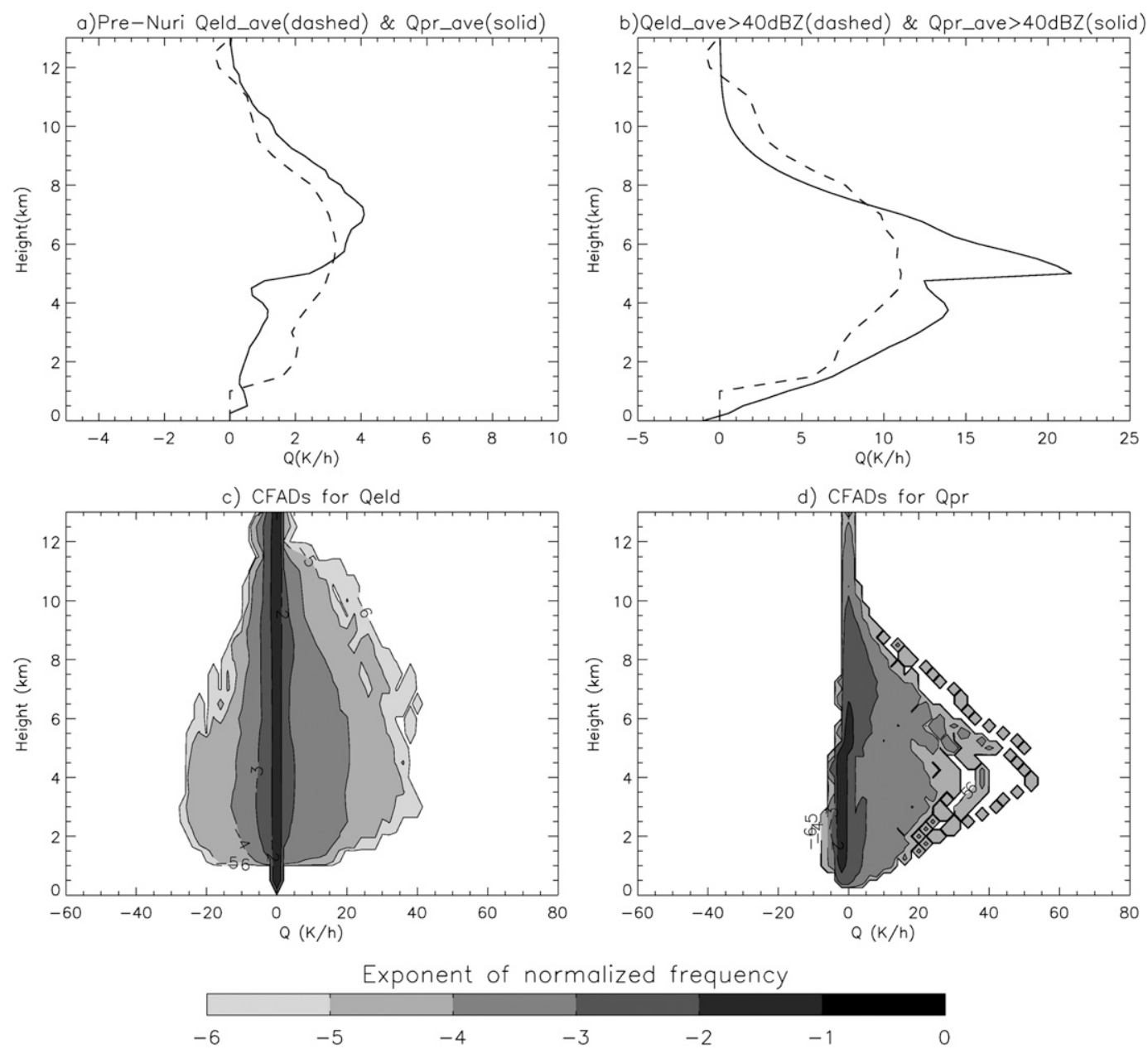

FIG. 5. (a) Net heating rate $\left(\mathrm{K} \mathrm{h}^{-1}\right)$ profiles as in Fig. 2a, but for case 2 within the E3 area in Fig. 1f for ELDORA (dashed) and within the P2 area in Fig. 1e for TRMM PR (solid). (b) As in Fig. 2b, but for case 2. (c),(d) CFADs as in Figs. $2 \mathrm{c}$ and $2 \mathrm{~d}$, but for case 2 .

is hypothesized to be due to the smaller $850-200-\mathrm{hPa}$ vertical wind shear $\left(\sim 3.5 \mathrm{~m} \mathrm{~s}^{-1}\right)$ than for the pre-Sinlaku circulation $\left(\sim 8.24 \mathrm{~m} \mathrm{~s}^{-1}\right)$, which was at a higher latitude and interacting with a midlatitude trough. Another factor is that the southern convective burst had a lower-tropospheric inflow trajectory of warm, moist air from the southwest (Elsberry and Chollet 2010).

The ELDORA observations document several convective towers with horizontal scales around $20 \mathrm{~km}$ in the E3 region (Fig. 1f) that extended above $13 \mathrm{~km}$. Three convective towers near $13^{\circ} \mathrm{N}$ between $143.8^{\circ}$ and $144.6^{\circ} \mathrm{E}$ extend above $15 \mathrm{~km}$ and have strong updrafts greater then $6 \mathrm{~m} \mathrm{~s}^{-1}$. Stretching associated with this vertical updraft and latent heat release are considered to lead to cyclonic vorticity generation in the lower troposphere. In an idealized numerical simulation by Nolan (2007), the vortex spins up when the maximum latent heating rate shifts from the upper troposphere to a maximum latent heating rate in the mid- and lower troposphere with minimum (negative) values in the near-surface layer.

Comparison of the CFAD for the TRMM PR (Fig. 5d) with that of the ELDORA (Fig. 5c) indicates the features that a new PR algorithm would need to replicate. Note that the SLH has correctly depicted a lowertropospheric maximum in the heating rates. As in the pre-Sinlaku case, the major correction required of the new algorithm would be in the cooling rates for almost all frequency contours (Fig. 5d). While certain uncertainties exist in the present $Q_{\mathrm{ELD}}$ algorithm, the new PR algorithm should replicate the key $Q_{\mathrm{ELD}}$ heating and cooling rate structure differences between case 2 (Fig. 5c) and case 1 (Fig. 2c).

Evidence that the northern convective burst was contributing to the low-level spinup in pre-Nuri was not found during the two ELDORA observations over the 


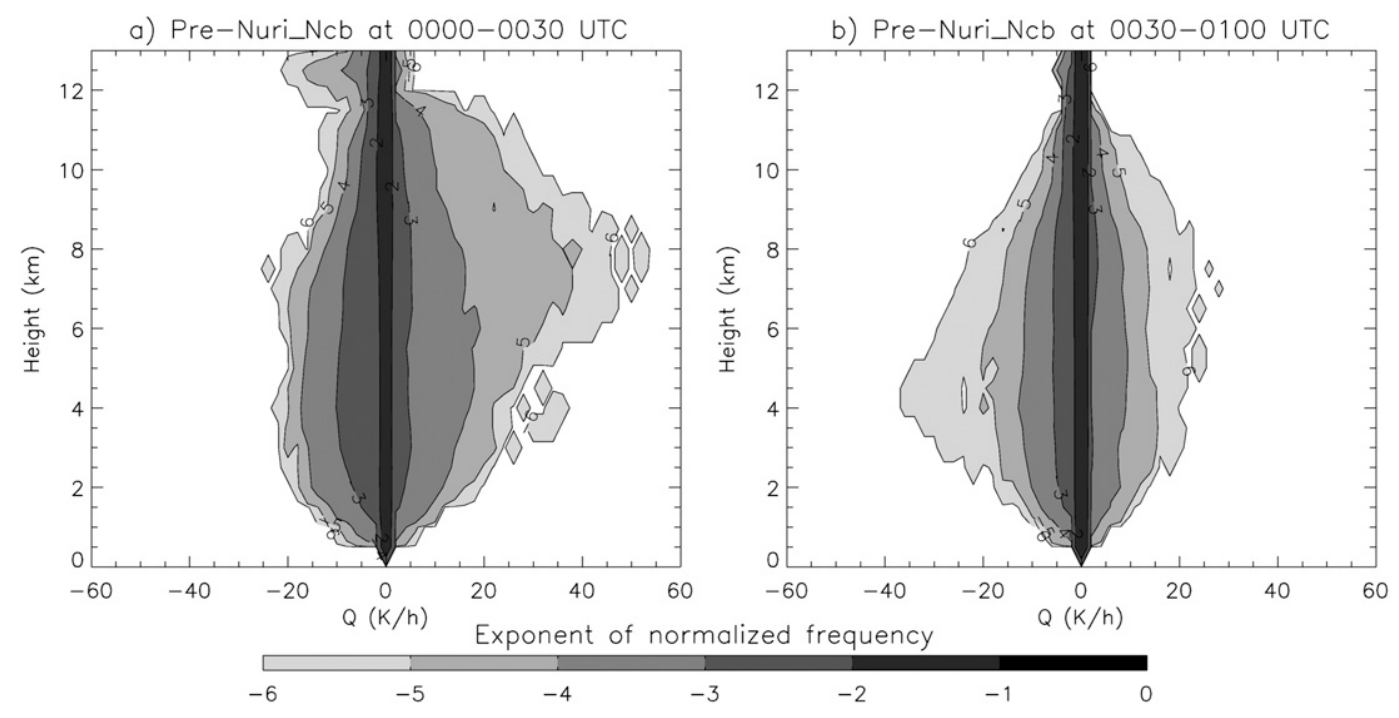

FIG. 6. As in Figs. 5c and 5d, but for the ELDORA-derived latent heating rates in the northern convective burst (Ncb) in the PreNuri_Ncb case at (a) 0000-0030 and (b) 0030-0100 UTC 16 Aug as defined in Table 1.

E2 region (Fig. 1f). Between 0000 and 0030 UTC (Fig. 6a), the latent heating maximum is clearly in the upper levels around $8 \mathrm{~km}$, and a deep layer with maximum evaporative cooling extends up to that level. Latent heating magnitudes decrease but the cooling magnitudes increase in the second set of ELDORA observations in the northern convective burst about 30 min later (Fig. 6b). Such an evolution is consistent with a large stratiform region with upper-level condensational heating at the earlier time being replaced with more evaporative cooling, which implies that this is the decaying phase of a MCS as in Fig. 4. Furthermore, this heating/cooling distribution contributes to midtropospheric vortex generation in the northern convective burst rather than a low-level vortex that might contribute to TC formation of pre-Nuri. Thus, the $Q_{\mathrm{ELD}}$ analyses of the northern convective burst during the two ELDORA missions do not provide evidence that the northern convective burst was the location for the mesoscale circulation that became TD Nuri. These two missions with flight tracks back and forth in advance of the same MCS do document a time evolution over about 20-30 min, which may be relevant to the nonstationary issue addressed by Guimond et al. (2011).

The requirement for a new PR algorithm to be able to distinguish between the latent heating and evaporative cooling profile differences between the southern convective burst in pre-Nuri (Fig. 5c) and in pre-Sinlaku (Fig. 2c) would apply in distinguishing the differences between the southern convective burst and the northern convective burst (Fig. 6a). While the present SLH algorithm may have reasonably replicated the upper-tropospheric heating maximum if a TRMM PR overpass had been available, it is likely from Figs. 5d and $2 \mathrm{~d}$ that near-zero cooling rates would have been calculated. Thus, it is proposed that a new TRMM PR algorithm that correctly addresses the saturated convective-scale downdrafts in association with the tilted convective updrafts would distinguish when mesoscale effects are contributing-or not-to tropical cyclone formation.

\section{Case studies of nondeveloping stages}

\section{a. TCS25 (case 3)}

The twenty-fifth synoptic circulation monitored by the TCS-08 scientists is labeled TCS25. This circulation did not develop into a tropical depression and became the most long-lived, nondeveloping tropical disturbance during the field experiment. As TCS25 was passing to the northeast of Guam on 29 August (Fig. 7a), an ELDORA mission between 0300 and 0330 UTC investigated a convective burst to the northwest (E4 in Fig. $7 \mathrm{c}$ ) of the $825-\mathrm{hPa}$ circulation center near $22.0^{\circ} \mathrm{N}$, $154.0^{\circ} \mathrm{E}$. The PR observed a similar area of deep convection (P4 in Fig. 7b) about $4 \mathrm{~h}$ after the ELDORA observations.

Satellite infrared and microwave imagery as in Fig. 7a seemed to indicate the potential development of TCS25. A sum of the TRMM PR reflectivity greater than $20 \mathrm{dBZ}$ over the P4 area in Fig. $7 \mathrm{~b}$ resulted in a net heating rate profile (Fig. 8a) that was quite similar in the upper troposphere to the profiles for pre-reintensification 

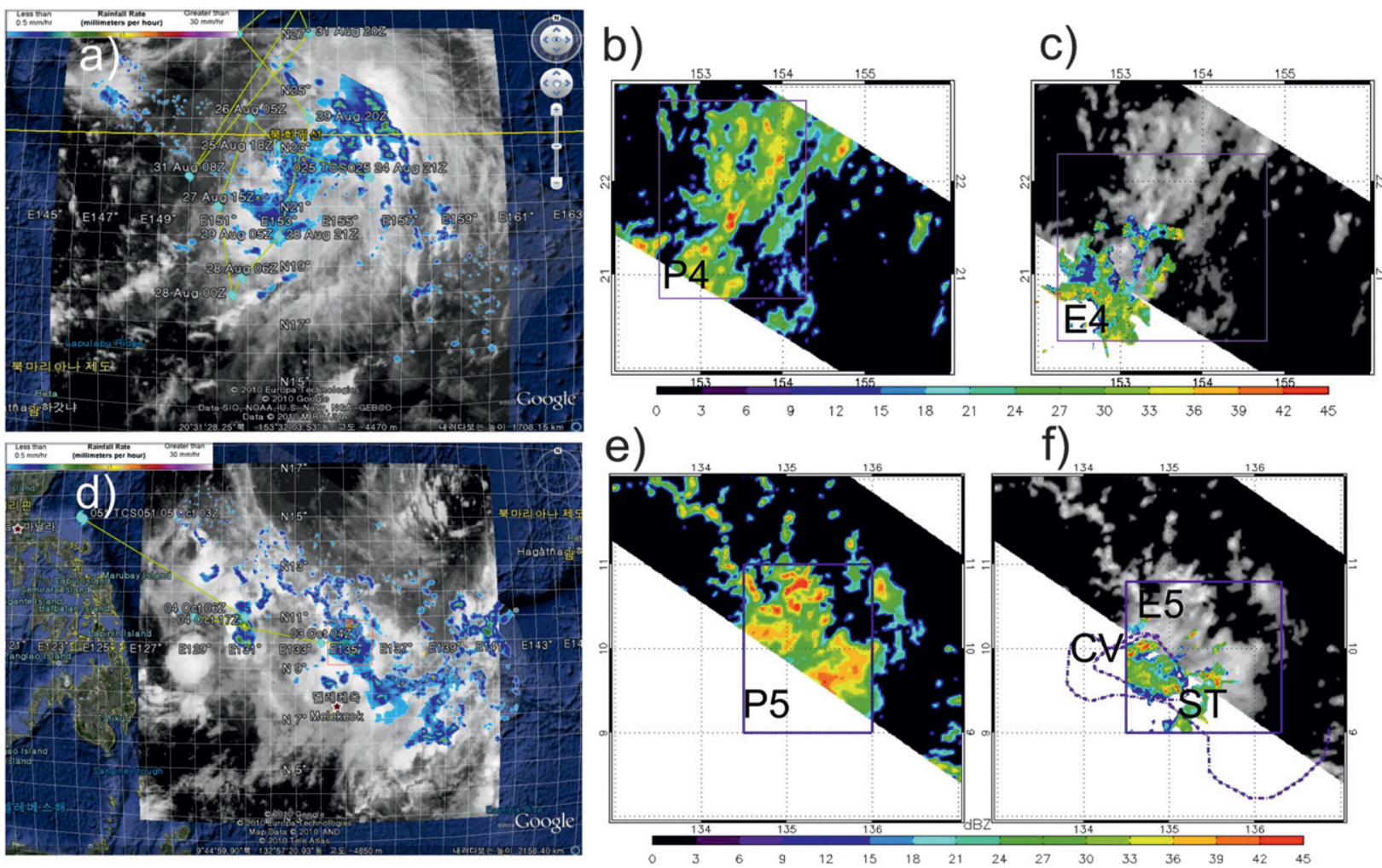

FIG. 7. As in Fig. 1, but for the two nondeveloping tropical disturbances (a)-(c) case 3 and (d)-(f) case 4 as defined in Table 1. The ELDORA-observed convective burst is $2^{\circ}$ west of the feature in (f), since the convective burst continued to move westward during the $10 \mathrm{~h}$ after the TRMM PR observations.

Sinlaku (Fig. 2a) and pre-Nuri (Fig. 5a). The near-zero lower-tropospheric net heating for TCS25 was also similar to the developing stage of pre-Nuri, and thus the PR profile does not appear to discriminate between a nondeveloper and a developer. Interestingly, the net $Q_{\text {ELD }}$ heating profile over the area E4 in Fig. 7c essentially has zero values throughout the layer, and especially above $4 \mathrm{~km}$, which is a marked departure from the TRMM PR net heating profile.

Because the fraction of the $Q_{\mathrm{PR}}$ pixels that had reflectivity values greater than $40 \mathrm{dBZ}$ was less than $5 \%$ in the nondeveloping cases, a threshold of greater than $35 \mathrm{dBZ}$ was adopted to represent the mesoscale effects in these cases. Summing the $Q_{\mathrm{PR}}$ over areas with reflectivities greater than $35 \mathrm{dBZ}$ for case 3 (Fig. 8b) results in a deep layer of net positive heating. Although the maximum heating rate is just above the freezing level as for the case 2 (Fig. 5b), the peak value is about $50 \%$ of the pre-Nuri value. By contrast, the net heating profile for ELDORA reflectivities greater than $35 \mathrm{dBZ}$ that highlight the mesoscale features has only a weak maximum of net heating rates in the $3-8-\mathrm{km}$ layer (Fig. 8b). Especially since the maximum value is about $1 \mathrm{~K} \mathrm{~h}^{-1}$, this ELDORA profile would not favor low-level convergence and development, which is consistent with the nondevelopment of TCS25.

The CFAD for the $Q_{\text {ELD }}$ (Fig. 8c) in TCS25 confirms that the lower-tropospheric heating rates are slightly larger than the cooling rates for the corresponding frequency contours of $10^{-4}, 10^{-5}$, and $10^{-6}$. In the 6-9-km layer, the $Q_{\mathrm{ELD}}$ cooling rates are generally larger than the heating rates. The tentative interpretation is that the TCS25 convective cluster did include embedded deep convection with latent heating extending deeper into the lower troposphere, but evaporative cooling and the associated downdrafts almost offset any tendency to spin up a low-level vortex. Furthermore, evaporative cooling in the upper-tropospheric convection in conjunction with the adjacent upper low system was tending to offset the warming aloft from the deep convection. Additional study of the ELDORA observations in this mission and subsequent missions in TCS25 is required to understand the complex latent heating and evaporative cooling profiles in TCS25. It will be demonstrated in Park et al. (2013) that two mesoscale models have heating and cooling rate profiles that are larger than the ELDORA profiles, and these models tend to overdeepen TCS25. 

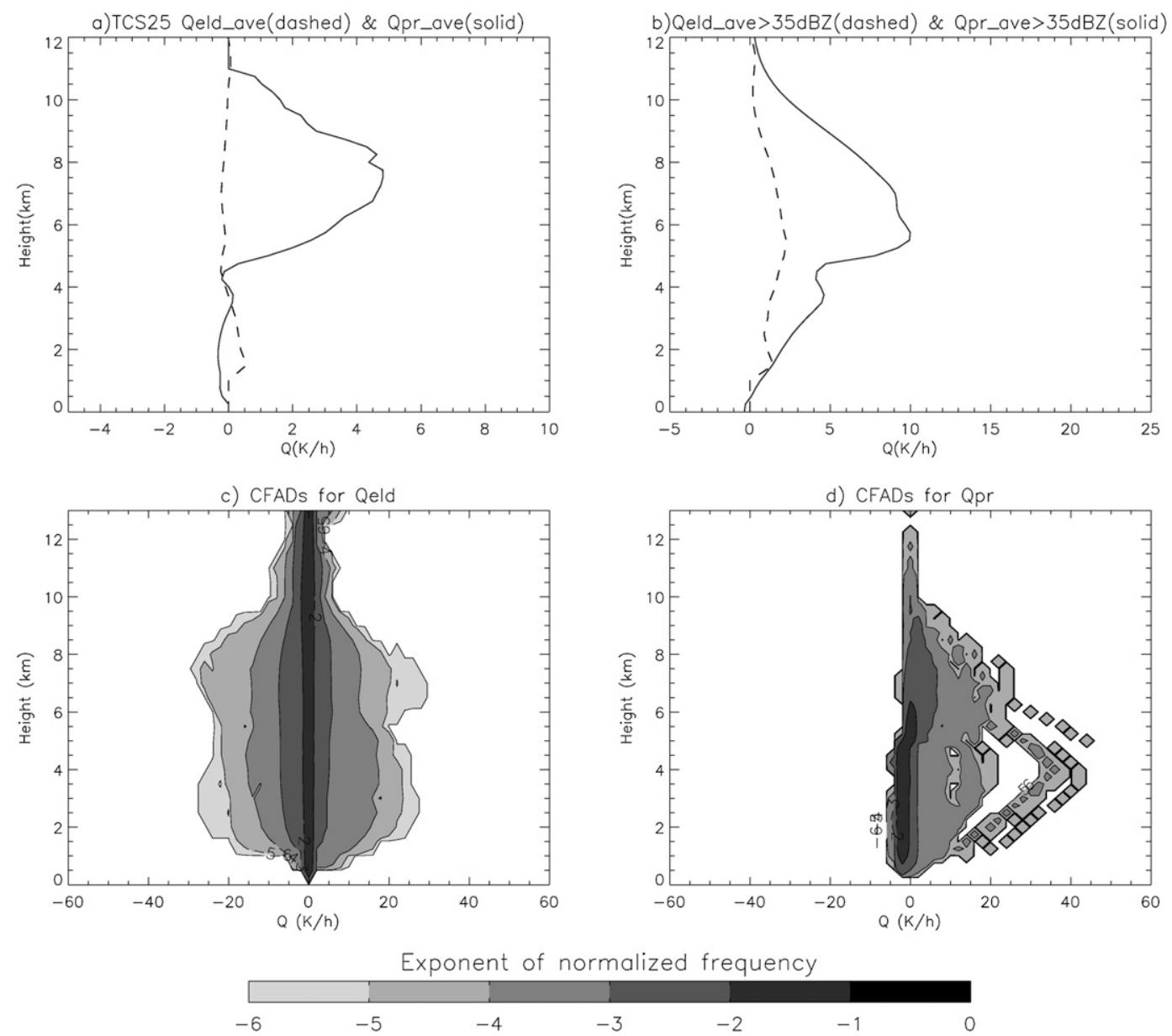

FIG. 8. (a) Net heating rate $\left(\mathrm{K} \mathrm{h}^{-1}\right)$ profiles as in Fig. 2a, but for case 3 TCS25 summed within the E4 area in Fig. 7c for ELDORA (dashed) and within the P4 area in Fig. 7b for TRMM PR (solid). (b) As in Fig. 2b, but for case 3, and the threshold reflectivity is lowered to $35 \mathrm{dBZ}$ for this nondeveloping stage. (c),(d) CFADs as in Figs. 2c and 2d, but for case 3 .

For the purpose of this study, the primary conclusion from the TRMM PR retrievals is that near-zero cooling rates are again revealed in the CFAD (Fig. 8d). The positive heating rates with values of about $20 \mathrm{~K} \mathrm{~h}^{-1}$ for a frequency contour of $10^{-4}$ are similar to the ELDORA rates for the corresponding frequency contour. However, a small number of pixels also exist with maximum heating rates of $40 \mathrm{~K} \mathrm{~h}^{-1}$ at an elevation of $4 \mathrm{~km}$, which may have been associated with embedded deep convection. Such a heating rate profile would have provided an indication of development rather than the observed nondevelopment. Whereas a new algorithm for the TRMM PR is clearly needed, this TCS25 case presents a complex situation that would need to be replicated.

\section{b. TCS51 (case 4)}

The TRMM PR observed a convective burst around 1630 UTC 3 October in the TCS51 circulation (red box in Fig. $7 b$ and P5 in Fig. 7e) when the center of the circulation was around $10^{\circ} \mathrm{N}, 113^{\circ} \mathrm{E}$ on 4 October (Fig. $7 \mathrm{~d}$ ). The ELDORA sampled well the convection southwest of the circulation center between 0200 and 0230 UTC 4 October (Fig. 7f). Note that the 10-h difference between the PR and the ELDORA observations in the TCS51 case may lead to relatively larger differences between the two retrievals than for the TCS25 case.

As in the case 2 and case 3, the profile of $Q_{\mathrm{PR}}>$ $20 \mathrm{dBZ}$ net heating averaged over the P5 area in Fig. 7e for this low-latitude TCS51 case has positive heating through the 0-12-km layer (Fig. 9a). The corresponding $Q_{\text {ELD }}>20 \mathrm{~dB} Z$ net heating averaged over the E5 area in Fig. $7 \mathrm{f}$ also has positive heating through the layers, but the maximum heating rate of about $2 \mathrm{~K} \mathrm{~h}^{-1}$ is a factor of 3 smaller than for $Q_{\mathrm{PR}}$. Using a threshold reflectivity value greater than $35 \mathrm{dBZ}$ to represent the mesoscale effects for this nondeveloping TCS51 case, the $Q_{\mathrm{PR}}$ 

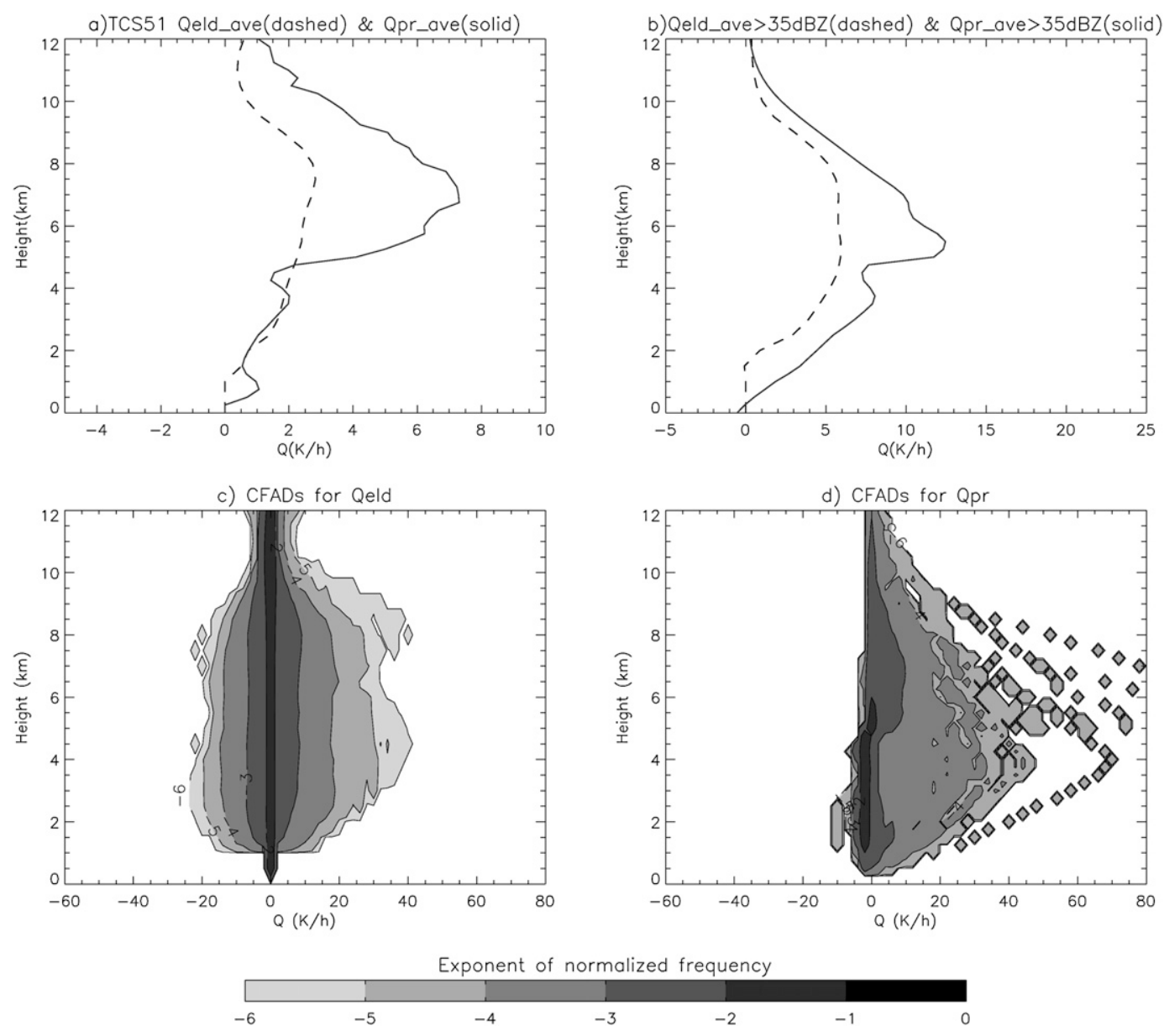

FIG. 9. (a) Net heating rate $\left(\mathrm{K} \mathrm{h}^{-1}\right)$ profiles as in Fig. 2a, but for case 4 summed within the E5 area in Fig. 7f for ELDORA (dashed) and within the P5 area in Fig. 7e for TRMM PR (solid). (b) As in Fig. 8b, but for case 4 TCS51. (c),(d) CFADs as in Figs. 8c and 8d, but for case 4.

profile (Fig. 9b) again has a similar peaked shape as in the pre-Nuri case (Fig. 5b), but the maximum value of about $12 \mathrm{~K} \mathrm{~h}^{-1}$ is about half the maximum in the preNuri case. Except for the differences in maximum $Q_{\mathrm{PR}}$ and $Q_{\text {ELD }}$ values, these net heating profiles have few characteristics that would distinguish between the nondeveloping TCS51 and the developing pre-Nuri case.

The CFAD for the $Q_{\mathrm{ELD}}$ for TCS51 (Fig. 9c) does have some distinguishing characteristics relative to that for pre-Nuri (Fig. 5c). Whereas the positive $Q_{\mathrm{ELD}}$ heating rates for the $10^{-4}, 10^{-5}$, and $10^{-6}$ frequency contours are more uniform in the vertical and the heating is confined below $10 \mathrm{~km}$ for TCS51, these frequency contours have lower-tropospheric heating maxima and extend positive heating to $12 \mathrm{~km}$ for pre-Nuri. The TCS51 case also has more uniform cooling rates between 2 and $8 \mathrm{~km}$, but the pre-Nuri case has a lowertropospheric maximum in cooling rates. Note also that the $Q_{\mathrm{ELD}}$ CFAD for the TCS25 case (Fig. 8c) also shares many of these distinguishing characteristics of nondevelopment for the TCS51 case: more uniform heating rates between 2 and $8 \mathrm{~km}$, heating rates confined below $10 \mathrm{~km}$, and more uniform cooling rates between 2 and $8 \mathrm{~km}$. To a large extent, the CFAD for the second ELDORA dataset in the northern convective burst in the pre-Nuri mission (Fig. 6b) also has these distinguishing characteristics of a nondeveloper, and indeed the associated MCS did decay (Fig. 4). Thus, the CFADs of the latent heating and cooling rates from the ELDORA retrievals appear to reveal some characteristics of the MCSs in nondeveloping cases that may be used to then distinguish when the mesoscale effects are contributing to development of a tropical depression.

\section{Mature TC rainbands}

The objective in this section is to briefly summarize some common characteristics of the latent heating and 
evaporative cooling rates from the ELDORA and TRMM PR retrievals of rainbands in mature Typhoons Jangmi (case 5) and Sinlaku (case 6) with the characteristics found in the developing and nondeveloping stages. [Because of space limitations, a detailed discussion of these cases is provided as supplemental material.]

The CFAD of latent heating and cooling rates from the combined three areas of ELDORA observations of outer rainbands in Typhoon Jangmi (Fig. S1c) has some of the characteristics of the developing-stage case 1 and case 2 and some characteristics of the nondevelopingstage cases 3 and 4 . The lower-tropospheric maximum of latent heating rates that also extend to $12 \mathrm{~km}$ for the $10^{-4}, 10^{-5}$, and $10^{-6}$ frequency contours is reminiscent of the pre-Nuri case. The -25 to $-50 \mathrm{~K} \mathrm{~h}^{-1}$ lower-tropospheric maxima in cooling rates for the corresponding frequency contours resemble the prereintensification Sinlaku case. The characteristics of the ELDORA CFAD (Fig. S1c) that are similar to the nondeveloping cases are the secondary maxima of both heating rates and cooling rates in the 6-9-km layer, with some suggestion that these cloud tops may only extend to near $10 \mathrm{~km}$. The convective structure responsible for these elevation differences in maximum heating and cooling rates are examined in Fig. S3 with radial-vertical cross sections through the outer rainband cells.

By contrast, the CFAD from the TRMM PR (Fig. S2d) has only a lower-tropospheric maximum in latent heating that closely resembles the CFAD for case 2 (Fig. 5d). Whereas this positive heating maximum in the lower troposphere would be appropriate for the E6 area (not shown), the TRMM PR retrievals also did not also detect the secondary maxima of net heating in the upper troposphere that were occurring in the E7 and E8 areas (not shown). More importantly, near-zero values of cooling rates for all frequency contours again indicate the need for a new TRMM PR algorithm that includes mesoscale effects associated with evaporative cooling for both the saturated convective-scale downdrafts in the lower troposphere and the upper-tropospheric downdrafts.

The CFAD from the ELDORA observations of an outer rainband in the reintensified Typhoon Sinlaku (Fig. S4c) at a high latitude has different characteristics from any of the previous five cases. Especially notable is the absence of $10^{-1}$ frequency contours in this CFAD, which is normalized over pixels in the entire volume. The interpretation is that the heating rates in this rainband are associated with a broad region of ascent over the warm front (see Fig. S5a), and thus few small cumulus clouds in the lower $7 \mathrm{~km}$ have been detected by the ELDORA. Nearly uniform $Q_{\text {ELD }}$ heating rates are calculated between 2 and $8 \mathrm{~km}$ for the $10^{-3}, 10^{-4}$, and $10^{-5}$ frequency contours (Fig. S4d). However, nearly equal cooling rates are also calculated at the same elevations for the corresponding frequency contours, which is consistent with the precipitation associated with the upgliding motion falling into dry air below and evaporating.

The CFAD for the TRMM PR (Fig. S4d) has a markedly different distribution of heating rates relative to the ELDORA CFAD. First, the $10^{-3}$ frequency contour has very small heating rates, especially below $4 \mathrm{~km}$. In the $10^{-4}-10^{-5}$ frequency band, scattered pixels indicate heating rates ranging from 20 to more than $80 \mathrm{~K} \mathrm{~h}^{-1}$. It is therefore likely that the CRM lookup table for the SLH does not encompass conditions that existed in this rainband of a typhoon undergoing extratropical transition. A consistent result with the previous five cases is the near-zero cooling rates, which is a large departure from the $Q_{\text {ELD }}$ cooling rates in Fig. S4c. Thus, the proposed new TRMM PR algorithm that would include mesoscale effects should also replicate the complex heating and cooling rates in the Sinlaku extratropical transition case.

\section{Summary and conclusions}

The ELDORA observations in two developing-stage (cases 1 and 2) and two nondeveloping-stage (cases 3 and 4) missions during TCS-08 provide a unique opportunity to document the latent heating and cooling rates associated with mesoscale processes. These ELDORA latent heating and cooling rates are considered to be in thermodynamic and dynamic equilibrium with the advective tendencies in the three-dimensional velocity field after a variational minimization and application of a three-step Leise filter (see appendix A). The third convective burst during the pre-reintensification period of Sinlaku (case 1) has been extensively studied by Sanabia (2010). The $80 \mathrm{~K} \mathrm{~h}^{-1}$ maximum in latent heating at $8-\mathrm{km}$ elevation is reasonable considering Sanabia documented a broad updraft exceeding $30 \mathrm{~m} \mathrm{~s}^{-1}$ in the upper troposphere. Similarly, the evaporative cooling rates of up to $-45 \mathrm{~K} \mathrm{~h}^{-1}$ in the lower troposphere are in the region of strong convective-scale downdrafts under the tilted updraft, which is consistent with the MCS conceptual models of Zipser (1977) and Houze (2004).

Comparisons are made with TRMM PR retrievals even though Shige et al. $(2004,2007)$ did not intend to represent the mesoscale processes in the SLH algorithm. The documentation of the near-zero TRMM PR cooling rates in case 1 (where the difference from the ELDORA retrieval is largest) and in each of the other five cases 

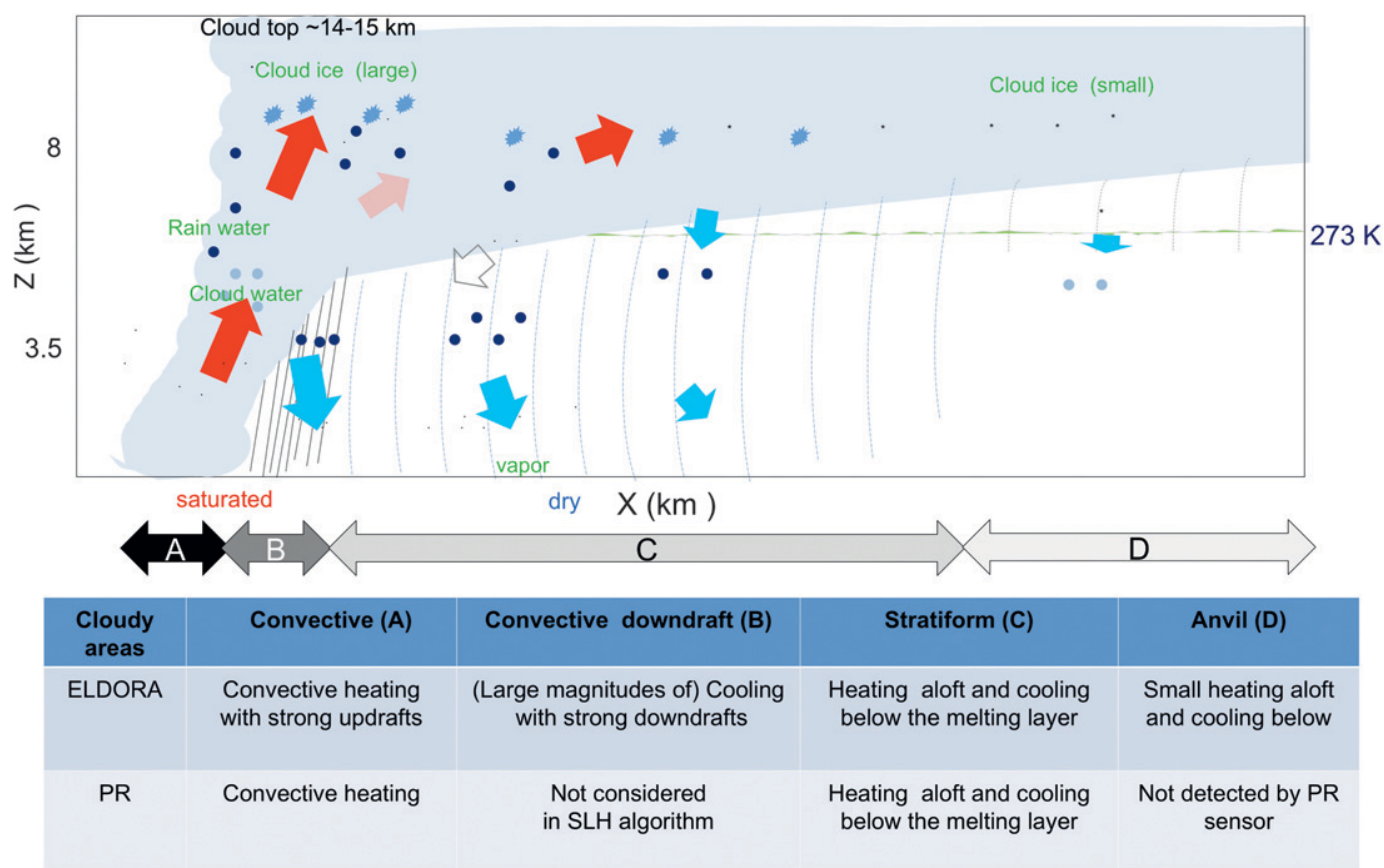

FIG. 10. Regions of heating and cooling maxima relative to the Houze (2004) schematic of a well-organized tropical MCS. The primary heating and cooling maxima described in this study are indicated by red and blue arrows, respectively. The capabilities of the ELDORA- and PR-based algorithms to detect heating and cooling rates in the cloud regions A-D are summarized in Table B1.

is not to unfairly criticize Shige et al. (2004, 2007). Rather, the purpose is to propose that a new TRMM PR algorithm should be developed that includes the mesoscale effects, and that the ELDORA retrievals would provide a basis for developing and testing such an algorithm.

A characteristic feature in the $Q_{\mathrm{ELD}}$ for the two developing cases is the increasingly larger heating magnitudes relative to cooling magnitudes for the less frequently occurring, but most intense, convection (section 3 ). In case 2, the low-level heating maximum was around $3 \mathrm{~km}$ in the southern convective cluster, but the northern convective complex had an uppertropospheric heating maximum with cooling below. Therefore, a more favorable mesoscale convective heating structure for tropical cyclone formation was demonstrated to be present in the southern convective burst than in the northern convective burst near the "sweet spot" of the easterly wave, which implies a critical role of the southern convective complex in the formation of Nuri.

Differences in heating and cooling rates between nondeveloping and developing TCs were also documented that are larger than the uncertainties in the retrievals (section 4). In two nondeveloping cases, both the maximum latent heating rates and the maximum cooling rates are more uniformly distributed over a deep layer, which implies stratiform rain areas with upper-level heating maxima and deep convective areas with low-level heating maxima are coexisting. In addition, some evidence exists that the nondeveloping cases have vertically limited convection compared to the developing cases.

The ELDORA retrievals in two rainbands in mature Typhoons Jangmi (case 5) and Sinlaku (case 6) indicate latent heating and cooling maxima in lower levels, resembling the developing cases. A common feature between these rainbands and the nondeveloping cases is the nearly symmetric distributions of maximum heating and cooling rates. Particularly in the case of Typhoon Sinlaku beginning extratropical transition, it is evident that the TOGA COARE database for developing the SLH algorithm did not include such convective conditions.

This study provides evidence that a new TRMM PR algorithm should be developed that would represent the saturated convection-scale downdrafts of tropical MCSs (region B in Fig. 10), and it is proposed that the $Q_{\mathrm{ELD}}$ retrievals may provide a basis for developing such an algorithm. The TRMM PR SLH lookup table is based on CRM simulations in the TOGA COARE region, which may reasonably represent cloud microphysics in the convective updraft region (region A in Fig. 10) of the MCS. It is unknown whether the evaporative cooling rates that were simulated by the CRM were of the 
proper magnitude for a variety of environmental conditions, since Shige et al. $(2004,2007)$ combined the heating and cooling rates of convective pixels and found net positive heating. Diabatic cooling associated with the strong convective-scale downdrafts in region $\mathrm{B}$ will be larger than the moderate or small cooling rates in the stratiform and anvil regions. One systematic bias of current CRM simulations is that the model-derived reflectivity is larger than observed reflectivities (Rogers et al. 2007). Thus, the simulated reflectivities may indicate a systematic bias toward larger heating and smaller cooling magnitudes. In a follow-on study (Park et al. 2013), the ELDORA-derived latent heating and cooling rates will be compared with numerical modelsimulated latent heating and cooling rates for these cases during the TCS-08 field experiment.

Development of a new TRMM PR algorithm that properly treated the tropical MCS effects would allow production of a legacy TRMM database that would be useful for diagnostic studies of tropical cyclone formations (and other high-impact tropical weather systems) since the 1998 launch date. Similarly, the legacy database could be used for specifying initial and validation conditions for numerical simulations on a range of time and space scales. In addition, the Global Precipitation Measurement (GPM; http://gpm.gsfc.nasa.gov/) satellite that will have a dual-frequency precipitation radar and a multiple-microwave imager with more frequent and wider areas of microwave observations is planned for launch in 2013 (Kirschbaum and Hou 2010). An application of the reliable satellite three-dimensional heating rates with increased temporal and spatial resolution is expected to open a new era of mesoscale diagnosis and simulation.

Acknowledgments. This study was performed during the first author's National Research Council Associateship at the Naval Postgraduate School (NPS), Monterey, California. The participation of the second author was funded by the Office of Naval Research and the National Science Foundation. Dr. Michael M. Bell provided a great contribution to this research by guiding the first author in the analysis and interpretation of the ELDORA observations that were provided by the Earth Observing Laboratory at the National Center for Atmospheric Research (NCAR). His contribution to this research is particularly appreciated. Prof. Patrick Harr is acknowledged for his leadership of the TCS-08 experiment and comments on this work, and many scientists at NPS, Naval Research Lab in Monterey, and NCAR did great jobs in conjunction with the ELDORA operation and processing. Profs. Takayabu and Shige, who did the challenging work developing the TRMM
PR SLH heating algorithm, provided guidance in interpreting this product. The NRL provided Goggle Earth files to make Figs. 1a, 1d, 7a, and 7d, and Figs. S1a and S1d. Mrs. Penny Jones provided skillful manuscript assistance. The first author thanks the editor and the reviewers for providing many constructive comments.

\section{APPENDIX A}

\section{Estimating the Heat Source Term in Thermodynamic Retrieval}

Dynamic and thermodynamic deviations in Roux and $\mathrm{Ju}$ (1990) and Roux et al. (1993) focused on the derivations of temperatures and pressures from the Doppler radar analyses of wind and reflectivity by solving equations of motion and the thermodynamic equation. This appendix describes how the heating source/sink associated with phase changes of hydrometeors may be derived as an extension of the Roux et al. methodology. The thermodynamic equation is expressed in terms of potential temperature $\theta$ as

$$
Q=C_{p} \pi\left[\frac{\partial \theta}{\partial t}+(\mathbf{V} \cdot \nabla) \theta\right]=R+\mathrm{LH}+D .
$$

Diabatic heating $Q$ at a Doppler radar-interpolated grid point is expressed as the time change and threedimensional advection of potential temperature, where $C_{p}$ is the specific heat of dry air at constant pressure; $\pi$ is nondimensional pressure; and $\mathbf{V}$ is Cartesian wind vector with $U, V$, and $W$ components in $x, y$, and $z$ directions. Diabatic heating is composed of heating and cooling terms associated with phase changes of water (LH), radiation $R$, and the molecular diffusion process $D$. The time tendency term $\partial \theta / \partial t, R$, and $D$ are assumed to be negligible compared to other terms. Expressing $\theta$ as an environmental temperature $\theta_{0}$ and temperature perturbation $\theta_{1}$, (A1) takes the simple form of a balance between three-dimensional advection and the latent heating terms, written as

$$
(\mathbf{V} \cdot \nabla)\left(\theta_{0}+\theta_{1}\right)=\frac{\mathrm{LH}}{C_{p} \pi} .
$$

This study employs virtual cloud temperature $\theta_{\mathrm{vc}}$ and the perturbation $\theta_{\mathrm{vc} 1}$, defined as

$$
\begin{gathered}
\theta_{\mathrm{vc}}=\theta\left(1+0.61 q_{v}-q_{c}\right), \\
\theta_{\mathrm{vc} 1}=\theta_{1}+\left(0.61 q_{v 1}-q_{c}\right) \theta_{0} .
\end{gathered}
$$


Cloudy air parcels are considered to contain dry air, water vapor, cloud particles (water or ice), and rainwater, where $q_{v}, q_{v 1}$, and $q_{c}$ are defined as vapor content, vapor content perturbation, and cloud content, respectively. The associated heat source $S\left(\theta_{\mathrm{vc}}\right)$, which is referred to as $Q_{\mathrm{ELD}}$ in this study, is then defined as follows:

$$
Q_{\mathrm{ELD}}=S\left(\theta_{\mathrm{vc}}\right)=(\mathbf{V} \cdot \nabla) \theta_{\mathrm{vc}}=W \frac{d \theta_{v 0}}{d z}+(\mathbf{V} \cdot \nabla) \theta_{\mathrm{vc} 1} .
$$

A key issue is to estimate $(\mathbf{V} \cdot \nabla) \theta_{\mathrm{vc} 1}$, which is derived from (A2) using (A3) and (A4), and defined as

$$
\begin{aligned}
(\mathbf{V} \cdot \nabla) \theta_{\mathrm{vc} 1}= & B_{T}=\frac{\mathrm{LH}}{C_{p} \pi}-W \frac{d \theta_{0}}{d z}-\theta_{0}\left(\mathbf{V} \cdot \nabla q_{c}\right)-q_{c} \frac{d \theta_{0}}{d z} \\
& +\theta_{0}(\mathbf{V} \cdot \nabla) 0.61 q_{v 1}+0.61 q_{v 1} \frac{d \theta_{0}}{d z}
\end{aligned}
$$

Neglecting $q_{v 1}$ and $q_{c}$ relative to 1 ,

$$
\begin{aligned}
(\mathbf{V} \cdot \nabla) \theta_{\mathrm{vc} 1}= & B_{T}=\frac{\mathrm{LH}}{C_{p} \pi}-W \frac{d \theta_{0}}{d z}-\theta_{0}\left(\mathbf{V} \cdot \nabla q_{c}\right) \\
& +\theta_{0}(\mathbf{V} \cdot \nabla) 0.61 q_{v 1}
\end{aligned}
$$

Thus, LH is increased by condensation or decreased by melting and evaporation depending on the saturation condition and is expressed as

$$
\mathrm{LH}=L_{v / s}\left[\delta_{s} K+\left(1-\delta_{s}\right) E\right]-L_{F} M,
$$

where $L_{v / s}$ is the latent heat of vaporization or sublimation depending on temperature in the environment, $L_{f}$ is the latent heat of freezing, $\delta_{s}$ is an indicator of saturation ( 1 for saturated air and 0 for unsaturated air), $K$ is the condensation rate, $E$ is the evaporation rate, and $M$ is the melting rate that is estimated following Leary and Houze (1979).

The unknown terms in (A6b) are obtained from continuity equations for the various hydrometeors. First, the continuity equation of rainwater content contains a rain production term $F\left(q_{r}\right)$ that is calculated from the radar observations, as shown:

$F\left(q_{r}\right)=\frac{\partial q_{r}}{\partial t}+(\mathbf{V} \cdot \nabla) q_{r}+\frac{1}{\rho_{0}} \frac{\partial}{\partial z}\left(\rho_{0} v_{t} q_{r}\right)=\mathrm{AC}-E$,

where the rainwater time tendency term is assumed to be negligible assuming stationary conditions for hydrometeors; and $q_{r}$ and $v_{t}$ are the rain drop content and terminal velocity, respectively, which can be deduced from the
ELDORA reflectivities $Z$ through the $Z-q_{r}$ relationship depending on the air temperature in the environment [see Roux et al. (1993) for parameters in the relationship]. In (A8), AC is the rate of transformation of cloud particles to rain through autoconversion and collection, and $E$ is the rate of evaporation of rainwater into vapor. An increase of rainwater $(F>0)$ indicates that rainwater is converted from cloud water or ice, which implies a saturated state. By contrast, a decrease of rainwater $(F<0)$ indicates that rainwater is being evaporated, which implies a nonsaturated state. Thus, the saturation condition $\delta_{s}$ is obtained from the estimated $F\left(q_{r}\right)$. Because of some uncertainties in the estimation of $F\left(q_{r}\right)$, air was considered to be saturated only in the region where $F\left(q_{r}\right)>-1 \mathrm{mg} \mathrm{kg}^{-1} \mathrm{~s}^{-1}$.

In addition, the continuity equations for vapor and cloud water are

$$
\frac{\partial q_{v 1}}{\partial t}+(\mathbf{V} \cdot \nabla) q_{v 1}+W \frac{\partial q_{v 0}}{\partial z}=-K+E,
$$

$$
\frac{\partial q_{c}}{\partial t}+(\mathbf{V} \cdot \nabla) q_{c}=+K-\mathrm{AC}
$$

The stationary assumption for hydrometeors is again made, and thus the time tendency terms are omitted.

The unknown terms in (A6) are obtained differently in saturated and unsaturated air conditions.

(i) If air is saturated $\left\{\delta_{S}=1 ;\left[F\left(q_{r}\right)\right]>0\right\}$, then

$$
\begin{aligned}
\mathrm{AC} & =F\left(q_{r}\right), \quad K=-W\left(\frac{d q_{v}}{d z}\right)_{\mathrm{AS}} \\
(\mathbf{V} \cdot \nabla) q_{v 1} & =W\left[\left(\frac{d q_{v}}{d z}\right)_{\mathrm{AS}}-\frac{d q_{v 0}}{d z}\right] \\
(\mathbf{V} \cdot \nabla) q_{c} & =-F\left(q_{r}\right)-W\left(\frac{d q_{v}}{d z}\right)_{\mathrm{AS}},
\end{aligned}
$$

where $\left(d q_{v} / d z\right)_{\text {AS }}$ is the vertical gradient of water vapor along a pseudoadiabat representative of the thermodynamic characteristics in the region of upward motion.

(ii) If air is unsaturated $\left[\delta_{S}=0 ; F\left(q_{r}\right)<0\right]$, then $K=0$, and $\mathrm{AC}=0$,

$$
\begin{aligned}
E & =-F\left(q_{r}\right) \\
(\mathbf{V} \cdot \nabla) q_{v 1} & =W \frac{d q_{v 0}}{d z}-F\left(q_{r}\right) \\
(\mathbf{V} \cdot \nabla) q_{c} & =0
\end{aligned}
$$

Accordingly, the $(\mathbf{V} \cdot \nabla) \theta_{\mathrm{vc} 1}$ term in (A6a) can then rewritten as 
TABLE B1. Summary of sensitivity tests for a small array with dimensions of [40, 40, 31] in which the control $Q_{\mathrm{cnt}}$ uses the vertical velocity calculated on a 1-km horizontal grid based on the three-dimensional variational (3DVAR) method with $\lambda_{\mathrm{mc}}=1000$, and the values along the flight track are not included. The sounding from the Yap, Micronesia, station PTYA $\left(9.48^{\circ} \mathrm{N}, 138.08^{\circ} \mathrm{E}\right)$ at $0000 \mathrm{UTC}$ $27 \mathrm{Sep}$ is used as the environmental condition. The sensitivity tests in the second, third, and fourth columns are indicated in boldface font: $Q_{\lambda_{m c}=100}$ is from the same three-dimensional variational method but with $\lambda_{\mathrm{mc}}=100 ; Q_{\mathrm{res}=500 \mathrm{~m}}$ is the calculation on a 500-m horizontal grid; $Q_{\text {ced }}$ uses winds calculated from the CEDRIC method; $Q_{\text {drysnd }}$ is for a sounding profile from Jeju $\left(33.28^{\circ} \mathrm{N}, 126.16^{\circ} \mathrm{E}\right)$. The $Q_{\mathrm{ELD}}$ value calculated over a wide array $[175,110,31]$ that includes vertical velocity errors along the flight track is shown in the last column. Cross sections of the various retrievals are shown in Fig. B1, while a cross section of $Q_{\mathrm{ELD}}$ is shown in Fig. S1 and the corresponding CFAD analysis is in Fig. S2.

\begin{tabular}{|c|c|c|c|c|c|c|c|}
\hline \multicolumn{2}{|c|}{ Sensitivity test } & $Q_{\mathrm{cnt}}$ & $Q_{\lambda_{m c}=100}$ & $Q_{\text {res }=500 \mathrm{~m}}$ & $Q_{\text {ced }}$ & $Q_{\text {drysnd }}$ & $Q_{\mathrm{ELD}}$ \\
\hline \multirow{2}{*}{\multicolumn{2}{|c|}{$\begin{array}{l}\text { Flight track error } \\
\text { Horizontal resolution }(\mathrm{km})\end{array}$}} & No & No & No & No & No & Yes \\
\hline & & 1 & 1 & 0.5 & 1 & 1 & 1 \\
\hline \multirow{3}{*}{$\begin{array}{l}\text { Retrieval of winds } \\
\text { Retrieval of heating }\end{array}$} & Synthesis method & 3DVAR & 3DVAR & 3DVAR & CEDRIC & 3DVAR & 3DVAR \\
\hline & $\lambda_{\mathrm{mc}}$ value (in case of $3 \mathrm{DVAR}$ ) & 1000 & 100 & 1000 & - & 1000 & 1000 \\
\hline & Sounding & PTYA & PTYA & PTYA & PTYA & JeJu & PTYA \\
\hline
\end{tabular}

$$
\begin{aligned}
(\mathbf{V} \cdot \nabla) \theta_{\mathrm{vc} 1} & =B_{T}=B_{T 0}+\delta_{S} B_{T 1}^{S}+\left(1-\delta_{S}\right) B_{T 1}^{\mathrm{NS}} \\
B_{T 0} & =W\left(-0.61 \theta_{0} \frac{d q_{v 0}}{d z}-\frac{d \theta_{0}}{d z}\right)-\frac{L_{F}}{C_{p} \pi_{0}} M \\
B_{T 1}^{S} & =W\left(1.61 \theta_{0}-\frac{L_{v / s}}{C_{p} \pi_{0}}\right)\left(\frac{d q_{v}}{d z}\right)_{\mathrm{AS}}+\theta_{0} F\left(q_{r}\right) \\
B_{T 1}^{\mathrm{NS}} & =W\left(\frac{L_{v / s}}{C_{p} \pi_{0}}-0.61 \theta_{0}\right) F\left(q_{r}\right) .
\end{aligned}
$$

As mentioned above, most of terms are known, but $\gamma$ (vertical gradient temperature of water vapor content along a saturated adiabat) requires the temperature retrieval. Following Iribarne and Godson (1981), $\gamma$ is represented as a function, as shown:

$$
\begin{aligned}
& \gamma=-\left(\frac{g}{L_{v / s}}\right)(1-G), \quad G=\frac{1+x}{1+x y}, \quad x=\frac{\varepsilon L_{v / s} e_{s}}{R T P}, \\
& y=\frac{\varepsilon L_{v / s}}{C_{p} T}
\end{aligned}
$$

where $T$ is temperature, $P$ is pressure, $\varepsilon=0.622, R$ is the universal gas constant, and $e_{s}$ is the water vapor pressure at saturation that depends on temperature.

After linearization of $\gamma$ using (A14), some equations in (A13) are modified to

$$
\begin{aligned}
B_{T}+\delta_{S} \beta \theta_{\mathrm{vc} 1} & =B_{T 0}+\delta_{S}\left(B_{T 1}^{S}+\beta \theta_{\mathrm{vc} 1}\right)+\left(1-\delta_{S}\right) B_{T 1}^{\mathrm{NS}} \\
B_{T 1}^{S} & =W\left(1.61 \theta_{0} \frac{L_{v / s}}{C_{p} \pi_{0}}\right) \gamma_{0}+\theta_{0} F\left(q_{r}\right) \\
\beta & =W g G_{1}\left(-\frac{1}{C_{p} \pi_{0}}+\frac{1.61 \theta_{0}}{L_{v / s}}\right)
\end{aligned}
$$

where $\gamma_{0}$ is the vertical gradient of water content for a wet adiabat defined by the environmental values of pressure and temperature. Equation (A15) is consistent with wet adiabat to the retrieved temperature through $\delta_{S} \beta \theta_{\mathrm{vc1}}$. Thus, this equation is solved simultaneously with $\theta_{\mathrm{vc} 1}$, which is deduced from the three equations of motion in the $x, y$, and $z$ directions and $B_{T}$ [more details on the $\theta_{\mathrm{vc} 1}$ retrieval are given in Roux et al. (1993)].

\section{APPENDIX B}

\section{Uncertainties in the ELDORA Retrievals}

Estimating the vertical velocities introduces uncertainties depending on the options chosen in the retrieval procedure that include (i) an inevitable inclusion of vertical velocity calculation errors along the flight track, (ii) weighting value $\lambda_{\mathrm{mc}}$ for the mass continuity equation in the variational method, (iii) the horizontal resolution for the analysis, (iv) use of three-dimensional variational technique [rather than a column integration of the mass continuity equation that is called Custom Editing and Display of Reduced Information in Cartesian Space (CEDRIC; Mohr et al. 1986)], and (v) representativeness of the environmental sounding. The sensitivity of the $Q_{\mathrm{ELD}}$ values to these dependent factors is summarized in Table B1.

The control $Q_{\text {cnt }}$ (Fig. B1a) is calculated for a small box array that includes the erect convective cell developed near $r=10 \mathrm{~km}$ radially outside of an old convective system in the outer rainband of Typhoon Jangmi at 2355 UTC 26 September. In Fig. B1a $Q_{\text {cnt }}$ has similar distributions and magnitudes of reflectivities, vertical velocities, and latent heating rates compared to the $Q_{\text {ELD }}$ (see Figs. S2a-e), which indicates the inclusion of flight-track-related errors does not impact the 
a) $Q_{c n t}$
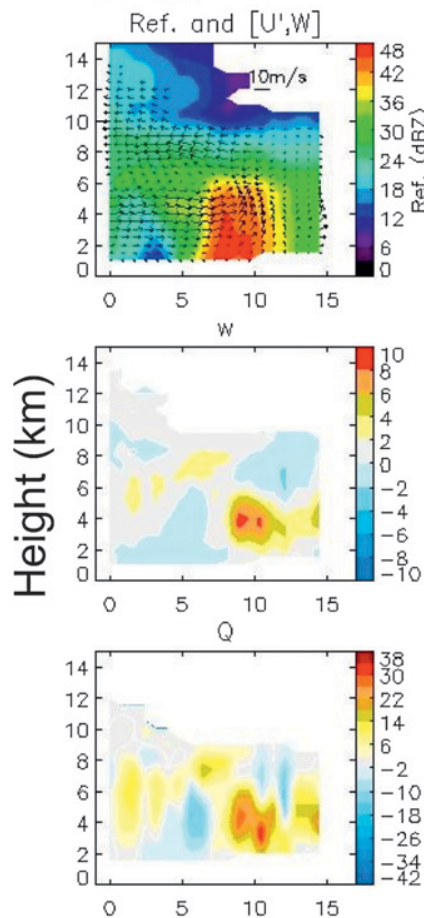

b) $Q_{\lambda m c=100}$

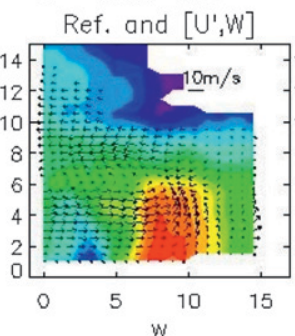

c) $Q_{\text {res }=500 m}$ Ref, and $\left[\mathrm{U}^{\prime}, \mathrm{W}\right]$
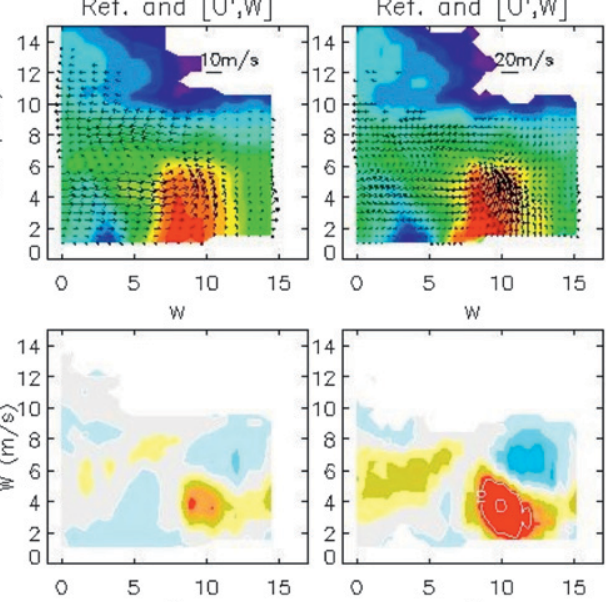

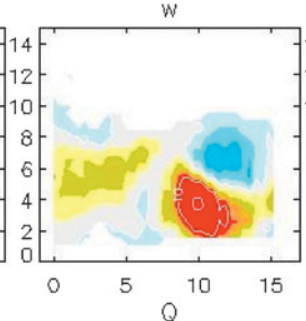

d) $Q_{\text {ced }}$
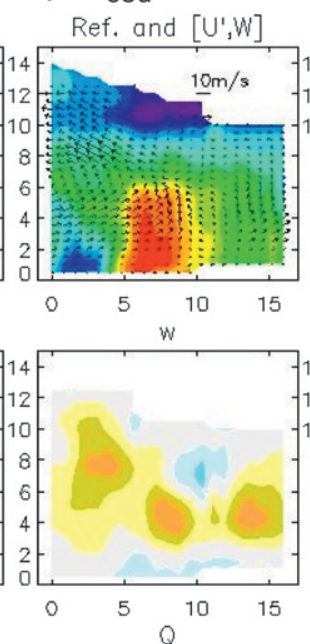

Q
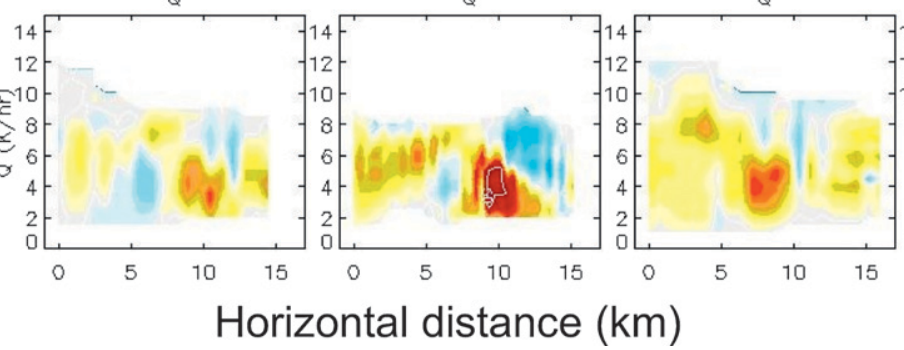

e) $Q_{\text {drysnd }}$
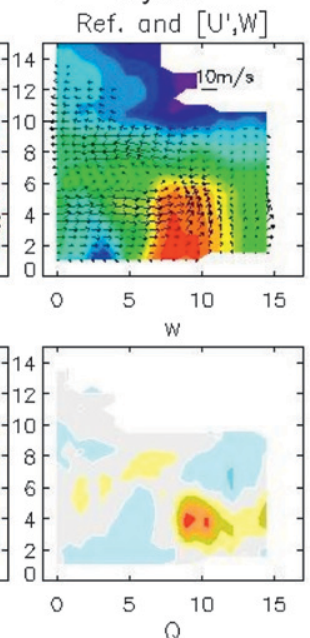

Horizontal distance $(\mathrm{km})$

FIG. B1. Cross sections of Doppler radar reflectivity (Ref.) and anomalous zonal $\left(U^{\prime}\right)$ and vertical $(W)$ winds, and the retrieved latent heating rates for the sensitivity tests of (a) $Q_{\mathrm{cnt}}$, (b) $Q_{\lambda_{m c}=100}$, (c) $Q_{\text {res=500m }}$, (d) $Q_{\text {ced }}$, and (e) $Q_{\text {drysnd }}$ described in Table B1.

retrieval. A change of $\lambda_{\mathrm{mc}}$ from the current choice (1000) to 100 in the $Q_{\lambda_{\mathrm{mc}}=100}$ retrieval did not cause any significant change in magnitudes and structures of the latent heating rate (Fig. B1b), except with a small decrease in magnitude relative to $Q_{\mathrm{cnt}}$. An increase in the horizontal resolution from $1 \mathrm{~km}$ to $500 \mathrm{~m}$ results in an increase in maximum vertical velocity from 8 to $12 \mathrm{~m} \mathrm{~s}^{-1}$ and $Q_{\text {res }=500 \mathrm{~m}}$ from 38 to $50 \mathrm{~K} \mathrm{~h}^{-1}$ (Fig. B1c). However, this resolution change did not change the overall horizontal and vertical distribution of heating and cooling. Note that a three-step Leise (1982) filter was applied prior to the thermodynamic retrieval to decrease computational errors in some terms, and the $Q_{\text {ELD }}$ with the 1-km horizontal resolution is somewhat smoothed relative to the solution with a 500-m horizontal resolution.

The NCAR software package CEDRIC solves for the vertical velocity with a strong constraint of a mass continuity equation subject to boundary conditions of $w=0$ at the upper and/or lower boundary. An upward integration with the lower boundary condition $w=0$ causes unreasonably high values at upper levels due to the accumulation of errors (not shown). The integrated vertical velocities subject to two boundary conditions ( $Q_{\text {ced }}$; Fig. B1d) have reasonable magnitudes and structures of upward motion and heating maxima that are consistent with $Q_{\text {cnt }}$ between $r=5$ and $10 \mathrm{~km}$. Although $Q_{\text {ced }}$ has somewhat different vertical velocities than $Q_{\mathrm{cnt}}$ between $r=5$ and $10 \mathrm{~km}$, these difference may not significantly influence the retrieved heating magnitudes.

While the $Q_{\text {cnt }}$ uses an atmospheric sounding from a tropical region, the sensitivity test with $Q_{\text {drysnd }}$ uses a sounding from a midlatitude region. Comparing $Q_{\mathrm{cnt}}$ with $Q_{\text {drysnd }}$ (Fig. B1e), the structure of heating rate is invariant but the magnitudes are somewhat changed by using such a different sounding.

\section{REFERENCES}

Bell, M. M., and M. T. Montgomery, 2010: Sheared deep vortical convection in pre-depression Hagupit during TCS08. Geophys. Res. Lett., 37, L06802, doi:10.1029/2009GL042313.

Bister, M., and K. A. Emanuel, 1997: The genesis of Hurricane Guillermo: TEXMEX analyses and a modeling study. Mon. Wea. Rev., 125, 2662-2682.

Bosart, B. L., W.-C. Lee, and R. M. Wakimoto, 2002: Procedures to improve the accuracy of airborne Doppler radar data. J. Atmos. Oceanic Technol., 19, 322-339. 
Cisneros, J., D. J. Raymond, and C. Lopez, 2010: High resolution analysis of the structure of a convective system in developing Typhoon Nuri. Preprints, 29th Conf. on Hurricanes and Tropical Meteorology, Tucson, AZ, Amer. Meteor. Soc., 9A.2. [Available online at https://ams.confex.com/ams/29Hurricanes/ techprogram/paper_168611.htm.]

Dunkerton, T. J., M. T. Montgomery, and Z. Wang, 2008: Tropical cyclogenesis in a tropical wave critical layer: Easterly waves. Atmos. Chem. Phys. Discuss., 8, 11 149-11 292, doi:10.5194/ acpd-8-11149-2008.

Elsberry, R. L., and P. A. Harr, 2008: Tropical Cyclone Structure (TCS08) field experiment: Science basis, observational platforms, and strategy. Asia-Pac. J. Atmos. Sci., 44, 209 231.

— mesoscale convective blowouts in tropical cyclone formations during TCS-08 experiment. Preprints, 29th Conf. on Hurricanes and Tropical Meteorology, Tucson, AZ, Amer. Meteor. Soc., 10A.2. [Available online at https://ams.confex.com/ams/ 29Hurricanes/techprogram/paper_168572.htm.]

Guimond, S. R., M. A. Bourassa, and P. D. Reasor, 2011: A latent heat retrieval and its effects on the intensity and structure change of Hurricane Guillermo (1997). Part I: The algorithm and observations. J. Atmos. Sci., 68, 1549-1567.

Hagos, S., and Coauthors, 2010: Estimates of tropical latent heating profiles: Commonalities and uncertainties. J. Climate, 23, 542558.

Harr, P. A., R. L. Elsberry, and J. C.-L. Chan, 1996: Transformation of a large monsoon depression to a tropical storm during TCM-93. Mon. Wea. Rev., 124, 2625-2643.

Hildebrand, P. H., and Coauthors, 1996: The ELDORA/ASTRAIA airborne Doppler weather radar: High-resolution observations from TOGA COARE. Bull. Amer. Meteor. Soc., 77, 213-232.

Houze, R. A., Jr., 2004: Mesoscale convective systems. Rev. Geophys., 42, RG4003, doi:10.1029/2004RG000150.

— - W.-C. Lee, and M. M. Bell, 2009: Convective contribution to the genesis of Hurricane Ophelia (2005). Mon. Wea. Rev., 139, 2778-2800.

Iribarne, J. V., and W. L. Godson, 1981: Atmospheric Thermodynamics. D. Reidel, $259 \mathrm{pp}$.

Kirschbaum, D., and A. Hou, 2010: Global Precipitation Measurement (GPM) mission. Meteor. Technol. Int., 3, 6-11.

Kummerow, C., W. Barnes, T. Kozu, J. Shiue, and J. Simpson, 1998: The Tropical Rainfall Measuring Mission (TRMM) sensor package. J. Atmos. Oceanic Technol., 15, 809-817.

Leary, C. A., and R. A. Houze, 1979: Melting and evaporation of hydrometeors in precipitation from the anvil clouds of deep tropical convection. J. Atmos. Sci., 36, 669-679.

Leise, J. A., 1982: A multi-dimensional scale-telescoped filter and data extension package. NOAA Tech. Memo. ERL WPL-82, 19 pp.

Matejka, T., and D. L. Bartels, 1998: The accuracy of vertical air velocities from Doppler radar data. Mon. Wea. Rev., 126, 92 117.

Mohr, C. G., L. J. Miller, R. L. Vaughn, and H. W. Frank, 1986: The merger of mesoscale datasets into a common Cartesian format for efficient and systematic analysis. J. Atmos. Oceanic Technol., 3, 143-161.

Montgomery, M. T., M. E. Nicholls, T. A. Cram, and A. B. Saunders, 2006: A vortical hot tower route to tropical cyclogenesis. J. Atmos. Sci., 63, 355-386.

— L. L. Lussier III, R. W. Moore, and Z. Wang, 2009: The genesis of Typhoon Nuri as observed during the Tropical
Cyclone Structure 2008 (TCS-08) field experiment-Part 1: The role of the easterly wave critical layer. Atmos. Chem. Phys. Discuss., 9, 19 159-19 203, doi:10.5194/acpd-9-191592009.

Nolan, D. S., 2007: What is the trigger for tropical cyclogenesis? Aust. Meteor. Mag., 56, 241-266.

Oye, R., C. Mueller, and S. Smith, 1995: Software for radar translation, visualization, editing, and interpolation. Preprints, 27th Conf. on Radar Meteorology, Vail, CO, Amer. Meteor. Soc., 359-361.

Park, M.-S., Y.-S. Choi, C.-H. Ho, C.-H. Sui, S. K. Park, and M.-H. Ahn, 2007: Regional cloud characteristics over the tropical northwestern Pacific as revealed by Tropical Rainfall Measuring Mission (TRMM) precipitation radar and TRMM Microwave Imager. J. Geophys. Res., 112, D05209, doi:10.1029/ 2006JD007437.

, A. B. Penny, R. L. Elsberry, B. J. Billings, and J. D. Doyle, 2013: Latent heating and cooling rates in developing and nondeveloping tropical disturbances during TCS-08: Radarequivalent retrievals from mesoscale numerical models and ELDORA. J. Atmos. Sci., 70, 37-55.

Reasor, P. D., M. D. Eastin, and J. F. Gamache, 2009: Rapidly intensifying Hurricane Guillermo (1997). Part I: Lowwavenumber structure and evolution. Mon. Wea. Rev., 137, 603-631.

Ritchie, E. A., and G. J. Holland, 1997: Scale interactions during the formation of Typhoon Irving. Mon. Wea. Rev., 125, 13771396.

Rogers, R. F., M. L. Black, S. S. Chen, and R. A. Black, 2007: An evaluation of microphysics fields from mesoscale model simulations of tropical cyclones. Part I: Comparisons with observations. J. Atmos. Sci., 64, 1811-1834.

Roux, F., and S. Ju, 1990: Single-Doppler observations of a West African squall line on 27-28 May 1981 during COPT 81: Kinematics, thermodynamics and water budget. Mon. Wea. Rev., 118, $1826-1854$.

_ , V. Marecal, and D. Hauser, 1993: The 12/13 January 1988 narrow cold-frontal rainband observed during MFDP/ FRONTS 87. Part I: Kinematics and thermodynamics. J. Atmos. Sci., 50, 951-974.

Sanabia, E., 2010: Re-intensification of Typhoon Sinlaku (2008). Ph.D. dissertation, Naval Postgraduate School, 233 pp.

Shige, S., Y. N. Takayabu, W.-K. Tao, and D. E. Johnson, 2004: Spectral retrieval of latent heating profiles from TRMM PR data. Part I: Development of a model-based algorithm. J. Appl. Meteor., 43, 1095-1113.

,,--- , and C.-L. Shie, 2007: Spectral retrieval of latent heating profiles from TRMM PR data. Part II: Algorithm improvement and heating estimates over tropical ocean regions. J. Appl. Meteor. Climatol., 46, 1098-1124.

Tao, W.-K., and Coauthors, 2003: Microphysics, radiation and surface processes in the Goddard Cumulus Ensemble (GCE) model. Meteor. Atmos. Phys., 82, 97-137.

- , and Coauthors, 2006: Retrieval of latent heating from TRMM measurements. Bull. Amer. Meteor. Soc., 87, 1555-1572.

Yuter, S. E., and R. A. Houze Jr., 1995: Three-dimensional kinematic and microphysical evolution of Florida cumulonimbus. Part II: Frequency distribution of vertical velocity, reflectivity, and differential reflectivity. Mon. Wea. Rev., 123, 1941-1963.

Zipser, E. J., 1977: Mesoscale and convective-scale downdrafts as distinct components of squall-line structure. Mon. Wea. Rev., 105, 1568-1589. 